\title{
Is seeing believing? Diver and video-based censuses reveal inconsistencies in roving predator estimates between regions
}

\author{
Jacob Asher ${ }^{1,2,3, *}$, Ivor D. Williams ${ }^{2}$, Euan S. Harvey ${ }^{3}$ \\ ${ }^{1}$ Joint Institute for Marine and Atmospheric Research, University of Hawaii at Manoa, Honolulu, Hawaii, 96822, USA \\ ${ }^{2}$ Habitat and Living Marine Resources Program, Ecosystem Sciences Division, Pacific Islands Fisheries Science Center, \\ National Oceanic and Atmospheric Administration, Honolulu, Hawaii, 96818, USA \\ ${ }^{3}$ Curtin University, School of Molecular and Life Sciences, Perth, Western Australia, 6845, Australia
}

\begin{abstract}
Coral reef research programs in Hawaii primarily use diver-based underwater visual censuses in $\leq 30 \mathrm{~m}$ depths to assess roving predator populations between the Main (MHI) and Northwestern Hawaiian Islands (NWHI). As a probable consequence of survey biases, results from some methods imply remarkably top-heavy trophic pyramids that potentially inflate the scale of differences between remote and populated regions. Other limitations include the absence of predator information in $>30$ m depths. To better understand regional differences, we compared shallow-water roving predator abundances and estimated predator length-frequencies between 2 diver-based visual assessment methods (stationary point count ['SPC'] and towed-diver) and 2 video sampling techniques (unbaited and baited remote underwater stereo-video systems: RUVS and BRUVS). We also surveyed 30-100 m ('mesophotic') roving predators using RUVS and BRUVS. As with diver-based assessments, RUVS and BRUVS sampled considerably more roving predators in the NWHI versus the MHI, with patterns remaining consistent between methods. However, the NWHI:MHI scales of difference for RUVS and BRUVS tended to be substantially lower than for diver surveys. The largest discrepancies were recorded for the giant trevally Caranx ignobilis, where NWHI:MHI abundance ratios varied by $>2$ orders of magnitude between diver SPC and all other methods. Although our results corroborate substantially higher roving predator densities in the NWHI, this study demonstrates that the application of different methods can result in strikingly dissimilar predator estimates. Continued assessments among survey techniques, coupled with the inclusion of mesophotic surveys, remain vital to improving understanding of predator populations, providing information that is properly aligned with management and conservation needs.
\end{abstract}

KEY WORDS: Roving predators · Methods comparisons · Main and Northwestern Hawaiian Islands

\section{INTRODUCTION}

In the absence of robust fishery dependent data, underwater visual diver censuses using open-circuit SCUBA remain the primary means for obtaining information on the abundance, biomass, and species richness of large-bodied, roving coral reef predators

*Corresponding author: jacob.asher@noaa.gov in the Hawaiian Archipelago. Several methods, including belt-transect, stationary point counts (SPC) and towed-diver surveys have been historically used to compare predator populations inhabiting $\leq 30 \mathrm{~m}$ habitats (herein denoted as 'shallow water') between the remote Northwestern Hawaiian Islands (NWHI) and the populated, heavily fished Main Hawaiian

(C) The authors 2019. Open Access under Creative Commons by Attribution Licence. Use, distribution and reproduction are unrestricted. Authors and original publication must be credited. 
Islands (MHI) (Friedlander \& DeMartini 2002, DeMartini \& Friedlander 2004, Nadon et al. 2012).

However, diver visual censuses remain subject to a number of biases, including different or varying responses of fishes to the presence of divers. For example, fish may avoid divers in areas of high spear fishing pressure, resulting in an underestimation of large-bodied, mobile species (MacNeil et al. 2008, Januchowski-Hartley et al. 2012, Lindfield et al. 2014, Gray et al. 2016). Conversely, the inflation of abundance estimates remains a concern in remote areas due to diver attraction (Cole et al. 2007, Watson \& Harvey 2007, MacNeil et al. 2008, Dickens et al. 2011, Lindfield et al. 2014). In addition, most commonly used diver censuses tend to overestimate highly mobile species (e.g. sharks and jacks), and the extent of that overestimation depends on the precise method and survey area dimensions used (Sandin et al. 2008a, Friedlander et al. 2010, Ward-Paige et al. 2010a, McCauley et al. 2012, Rizzari et al. 2014). Differences among observers, particularly when it comes to estimating the size of large roving piscivores, can also be a substantial source of survey error, although one that can be reduced by appropriate training and among-observer comparisons (Bell et al. 1985, Yulianto et al. 2015). Finally, divers on open-circuit SCUBA are largely limited to relatively shallow water $(\leq 30 \mathrm{~m})$, whereas roving predators can be highly abundant in deeper habitats down to $100 \mathrm{~m}$ and beyond (Nakamura et al. 2011, Papastamatiou et al. 2015, Fukunaga et al. 2016, Asher et al. 2017a). As many 'depth generalist' coral reef fish species are distributed across a broad range of depths, and in some cases are more abundant in deeper 'mesophotic' waters $>30 \mathrm{~m}$, underwater visual censuses do not assess large portions of some coral reef fish populations, potentially omitting information important to conservation and management.

To date, diver-based studies have consistently shown large differences in predator densities between populated versus unpopulated areas in the Pacific (Ayling \& Choat 2008, Nadon et al. 2012); however, pronounced discrepancies in the scale of those differences depend on the assessment method used (Dale et al. 2010, Graham et al. 2010, WardPaige et al. 2010b, McCauley et al. 2012, Ruppert et al. 2013, Rizzari et al. 2014). In the case of the NWHI versus MHI, scales of regional differences between predator abundance, density, and/or biomass estimates also vary according to survey methodology (Friedlander \& DeMartini 2002, Holzwarth et al. 2006, Nadon et al. 2012). For example, belt-transect survey data indicated that NWHI:MHI roving preda- tor biomass was 70-fold higher in the NWHI, whereas SPC-based predator biomass was $>50$-fold higher, signaling a general alignment between methods. In contrast, towed-diver surveys yielded predator density estimates for the most common roving predators in the NWHI-Aprion virescens, Caranx ignobilis, and Caranx melampygus - that were 11- to 90-fold lower than densities derived from belt transect surveys (Friedlander \& DeMartini 2002, Richards et al. 2011, Williams et al. 2011). As such, the survey methodology employed, as well as survey domain, appear to have large influences on the conclusions drawn about relative and absolute abundances of large-bodied, roving predatory species.

As a prospective alternative, remote underwater video surveys have several apparent advantages in comparison to diver-based methods. They are able to survey the (frequently substantial) portions of predator populations below the safe diving limits of opencircuit SCUBA depths (i.e. $>30 \mathrm{~m}$ ), which also means that they can provide data on deeper predatory species that are rarely seen by divers. Video surveys also generate permanent data records and are not affected by behavioral influences associated with diver attraction or avoidance. Baited remote underwater video sampling, in particular, is able to provide robust estimates of carnivorous fish abundance in comparison with other visual assessment methods, without generally decreasing the abundance and richness of herbivorous or omnivorous species (Harvey et al. 2007, Langlois et al. 2010, Watson et al. 2010, Rizzari et al. 2014). However, these methods have yet to be adopted as standard surveying and monitoring tools for reef fish and large-bodied roving predators in the Hawaiian Archipelago.

We address these issues in the Hawaiian Archipelago by comparing results from 4 survey techniques (diver SPC, towed-diver, unbaited and baited remote underwater stereo-video systems, herein denoted as 'RUVS' and 'BRUVS'), specifically comparing the different methods' estimates of differences in relative abundance and size between populated and remote parts of the archipelago. Diver SPC surveys conducted by the NOAA Pacific Islands Fisheries Science Center (PIFSC), Ecosystem Sciences Division (ESD) are small-scale censuses used to tally all conspicuous diurnally active species, including largebodied roving predators, as part of the Pacific Reef Assessment and Monitoring Program (RAMP; Fig. 1). However, because these surveys do not cover large reef areas, they tend to give limited opportunities to enumerate rare or patchily distributed species (Richards et al. 2011, Rizzari et al. 2014). Consequently, 


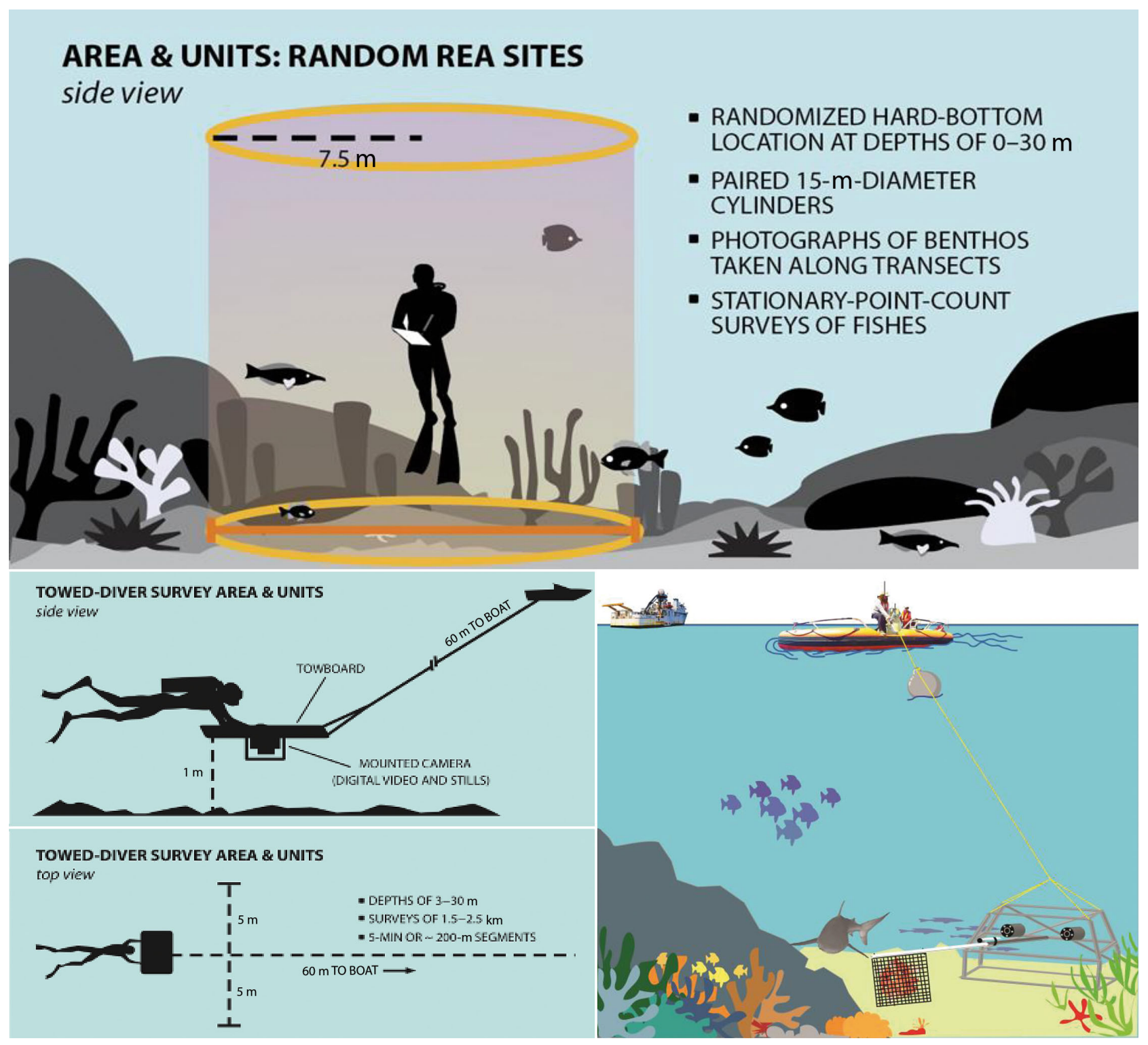

Fig. 1. Illustrations of methods assessed in this study. Top panel: diver stationary point count (SPC). Lower left panel: toweddiver survey. Lower right panel: unbaited remote underwater stereo-video systems (RUVS) and baited RUVS (BRUVS) surveys. REA: rapid ecological assessment. All graphics generated by NOAA

towed-diver surveys have been used to complement SPC surveys by targeting large-bodied, wide-ranging fishes $\geq 50 \mathrm{~cm}$ in length over much larger areas (Holzwarth et al. 2006, Richards et al. 2011).

Similarly, BRUVS are often preferred for predator surveys, although BRUVS may underestimate predator populations in very high-density locations as a result of count saturation within space-limited fields of view (Willis \& Babcock 2000, Cappo et al. 2004, Watson et al. 2005, Watson \& Harvey 2007, Wraith 2007, Stobart et al. 2015). Additional considerations include the potential inflation of density estimates due to fish being drawn from outside visible sampling areas, unknown areas of attraction as a byproduct of variable bait plume dispersion, alteration of fish behaviors, competitive exclusion, and/or preferential sampling of predator and scavenger populations with corresponding reductions to other functional groups (Harvey et al. 2007, Colton \& Swearer 2010, Dorman et al. 2012). In contrast, while RUVS may eliminate potential baiting effects, RUVS are rarely used in place of BRUVS due to higher amongsite variability and reduced sampling power, especially in areas where predators are scarce. To date, 
the comparability of RUVS and BRUVS with diverbased predator assessments, and their ability to discriminate regional scales of difference across populated versus remote parts of the Hawaiian Archipelago, have not been examined.

Previous studies evaluating baited remote underwater video versus diver-based surveys include suitability comparisons for assessing reef fish abundance, richness, and taxonomic diversity. Nevertheless, there are inconsistencies among reported results: for example, while some diversity measures were apparently better quantified using baited underwater video (Willis \& Babcock 2000, Willis et al. 2000, Watson et al. 2005), other studies have shown the opposite, with diver-surveys recording higher reef fish diversity (Stobart et al. 2007, Colton \& Swearer 2010). Thus, the interpretation of data collected from different methods, which have disparate biases and depth constraints, may result in very dissimilar estimates of coral reef fish populations, leading to conflicting management actions. Although there appears to be a clear need to increase the use of remote survey methods for surveying and monitoring reef fish and large-bodied roving predators, comparative studies which critically assess the strengths, advantages, weaknesses, limitations and biases of remote video sampling in comparison with other underwater visual census approaches remain vital.

As such, the main analysis objectives were to quantify the extent of sub-regional level differences in predator abundance ratios in $\leq 30 \mathrm{~m}$ depending on survey method and to incorporate deeper (30-100 m) RUVS and BRUVS data to compare against shallow-water datasets. Secondary goals included assessments of predator size distributions between methods in shallow water, along with an informal evaluation of the species encountered by the different methods.

\section{MATERIALS AND METHODS}

\subsection{Survey area}

The Hawaiian Archipelago is separated into 2 distinct sub-regions: the populated MHI (Hawaii to Niihau) and the NWHI (French Frigate Shoals to Kure Atoll). There are considerable human population density differences and associated impacts on reefs in the MHI; however, all are close to large population centers (Williams et al. 2011). In contrast, the remote NWHI have been closed to fishing with the establishment of the Marine Refuge in 2005, with subsequent protections added with the creation and expansion of the Papahānaumokuākea Marine National Monument (PMNM) in 2007 and 2016, respectively.

\subsection{Sampling procedures}

All SPC, towed-diver, RUV, and BRUV surveys were conducted in accordance with well-established protocols and are briefly described below. Diver SPC surveys last approximately 25 to $30 \mathrm{~min}$ each and were randomly located within $\leq 30 \mathrm{~m}$ hard-bottom habitats, with pairs of divers recording the number, size and species of fishes within adjacent, $15 \mathrm{~m}$ diameter cylinders along a $30 \mathrm{~m}$ transect line (Ayotte et al. 2015, McCoy et al. 2017). SPC counts followed a 2-stage process where divers spent the first 5 min building a list of species present within their cylinders, followed by a count phase whereby divers work successively through their species lists, recording numbers and size of each taxa in a series of rapid visual sweeps of their cylinders. In cases where these groups were present during the initial 5 min species enumeration period but not present during subsequent instantaneous sweeps, divers recorded their best estimates for numbers and sizes at the time they were first observed (and these are considered 'non-instantaneous' observations). Divers also recorded the number and sizes of any species that entered the cylinder for the first time after the species enumeration period. Depending on the period during which species were first observed, observations were classified as different observation types. However, for this analysis, all observation types were pooled into total counts per SPC.

During towed-diver surveys, a diver pair included one collecting data on benthos and one recording numbers, size and species of all fishes $>50 \mathrm{~cm}$ total length within a $10 \mathrm{~m}$ belt centered on the diver and up to $10 \mathrm{~m}$ ahead of the diver. Each towed diver survey lasts $50 \mathrm{~min}$, in which time divers were pulled $2.2 \mathrm{~km}$ average distance, with survey lengths and locations derived from a tracking GPS and layback algorithm. Towed-diver surveys were haphazardly located with the broad goal of being as widely spread as possible around each sampling location (e.g. island) and were typically in $15 \mathrm{~m}$ of water (Richards et al. 2011).

Diver SPC and towed-diver surveys were conducted by field teams running during daylight hours (08:00 to 16:00 h), as part of routine NOAA and PMNM/NWHI research and monitoring cruises from 2010 to 2016. Towed-diver surveys were conducted in the MHI in October-November 2010 and July- 
August 2016. In the NWHI, towed-diver surveys were completed in September 2010 and September 2016. SPC surveys were conducted in MHI in September 2012, August-October 2013, June-August 2015, and July-August 2016. SPC surveys in the NWHI occurred in August 2012, August 2014, JulyAugust 2015, and September 2016. All towed-diver and SPC surveys used in this analysis were conducted using consistent methodology between 2010 and 2016.

RUVS and BRUVS are operationally identical remote stereo-video surveys, other than that BRUVS are baited using $800 \mathrm{~g}$ of Japanese sanma Cololabris saira pulped into a wire mesh based $1.2 \mathrm{~m}$ in front of the stereo-cameras, while RUVS were deployed without bait bags. Shallow-water surveys $\leq 30$ m were randomly assigned to a subset of previously surveyed SPC site coordinates, with a minimum of 20 min between divers exiting the water and RUVS being deployed. Similarly, BRUVS were deployed at a subset of RUVS shallow water and mesophotic sites, with a minimum of 20 min between RUVS recoveries and BRUVS deployments. Each RUVS or BRUVS was deployed for a 60 min sampling duration and utilized paired Sony handycams calibrated using the CAL ${ }^{\mathrm{TM}}$ software package (www.seagis.com.au; Seager 2008) before and after each data collection effort following standard practice (Harvey \& Shortis 1998, Shortis \& Harvey 1998). Following research cruises, stereovideo files were reviewed, with predator species annotated to the lowest possible taxonomic level using EventMeasure-Stereo ${ }^{\mathrm{TM}}$ (Seager 2008).

Similar to diver-based surveys, all RUVS and BRUVS surveys were completed during daylight hours (08:00 to 16:00 h), and for these methods, all surveys were conducted between 2012 and 2014. In the MHI, surveys were completed between September and October 2012, running concurrent with SPC surveys. Supplementary RUVS and BRUVS were completed around southern Oahu in November 2013. In the NWHI, surveys were completed in May and August 2014 during 2 separate research deployments, with 2014 deployments running concurrent with SPC surveys.

For all methods, survey operations were conducted at 4 of the MHI (Oahu, Molokai, Lanai, and Maui) and 3 atolls in the NWHI (French Frigate Shoals, Pearl and Hermes Reef, Midway). While SPC and towed-diver surveys were completed at other locations in the archipelago, those were excluded from analysis so that we only used data from the same subset of islands for all methods. Finally, to increase consistency among surveys, we only utilized towed- diver, SPC, RUVS, and BRUVS surveys in hardbottom forereef or slope habitats. In total, we analyzed data from 588 SPC sites, 243 towed-diver surveys, 65 RUVS, and 39 BRUVS survey sites between 0 and $30 \mathrm{~m}$ in the MHI and from 325 SPC, 166 toweddiver, 39 RUVS, and 27 BRUVS survey sites in the NWHI. An additional 100 RUVS and 33 BRUVS surveys were examined from mesophotic depths in the MHI, along with 79 RUVS and 42 BRUVS surveys at mesophotic depths in the NWHI (Fig. 2).

\subsection{Target species}

We focused on large-bodied roving predators as described by Friedlander \& DeMartini (2002), Holzwarth et al. (2006), Williams et al. (2011), and Nadon et al. (2012). These included all shark (Carcharhinidae) and non-planktivorous jacks (Carangidae), along with the snapper Aprion virescens.

We assessed relative abundance ratios for several shark groupings: (1) all sharks (Galapagos Carcharhinus galapagensis, grey reef Carcharhinus amblyrhynchos, blacktip reef Carcharhinus melanopterus, sandbar Carcharhinus plumbeus, tiger Galeocerdo cuvier, and whitetip reef sharks Triaenodon obesus), (2) all reef sharks, i.e. the 4 shark species most closely associated with reefs in the Hawaiian Archipelago (C. galapagensis, C. amblyrhynchos, C. melanopterus, and $T$. obesus), excluding tiger and sandbar sharks that we considered to be less strongly associated with coral reefs or hard-bottom substrates (Nadon et al. 2012); (3) C. galapagensis and C. amblyrhynchos (denoted as 'GG sharks'), which are the numerically dominant shark species observed by divers in the NWHI.

We only had sufficient data to compare relative abundances (by method) for 4 individual species: $A$. virescens, T. obesus, Caranx ignobilis and Caranx melampygus. Finally, the pink snapper Pristipomoides filamentosus was sampled by RUVS and BRUVS in mesophotic depths at a small number of sites across the Hawaiian Archipelago; however, these bottom fish are nearly always found below depths surveyed by divers on open-circuit SCUBA and were excluded from analysis (Ellis \& Demartini 1995, Moffitt \& Parrish 1996).

\subsection{Analysis}

The primary objective was a comparison of the relative abundance of roving predators between NWHI 

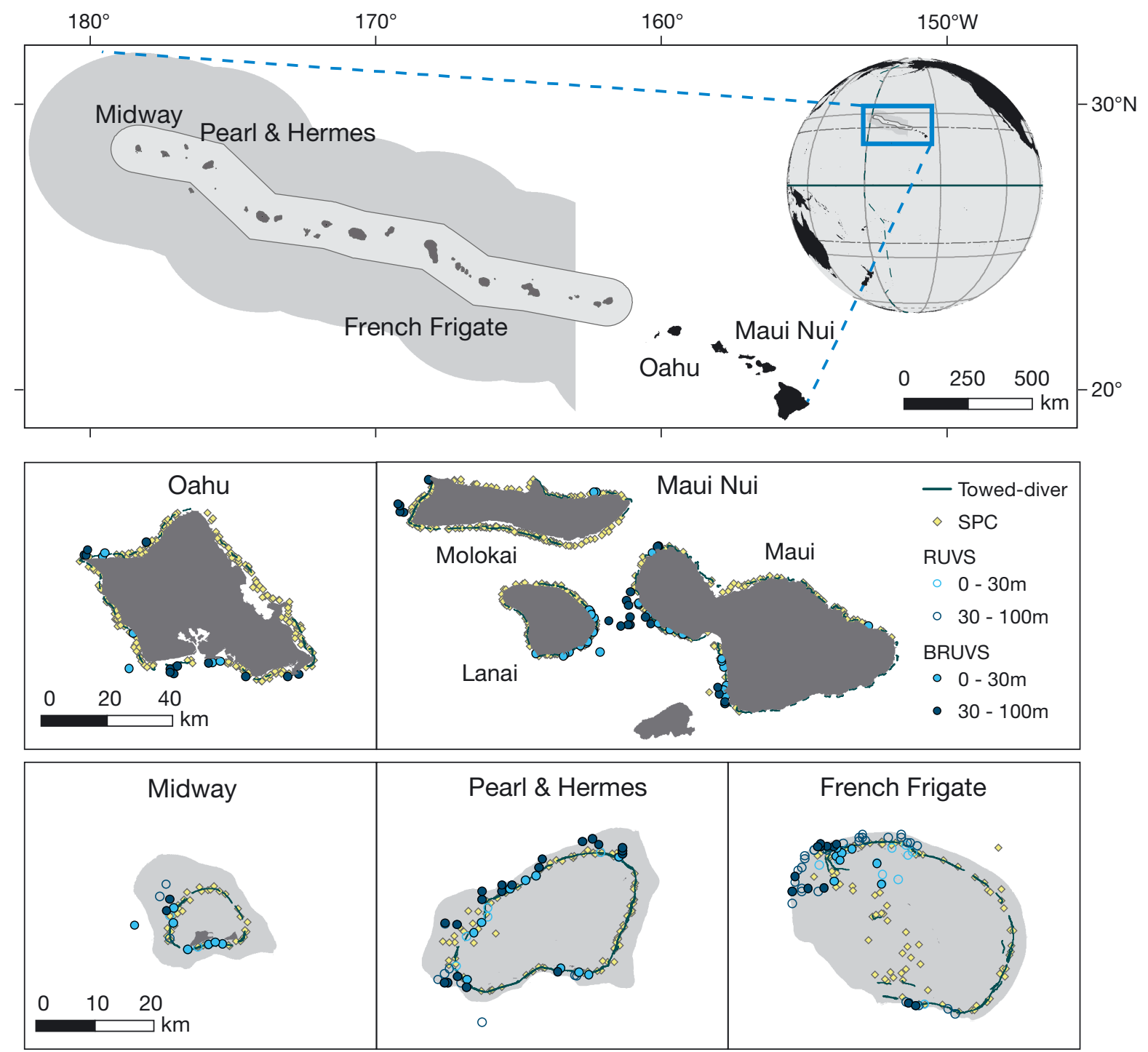

Fig. 2. Diver stationary point count (SPC), towed-diver, RUVS, and BRUVS surveys across the Hawaiian Archipelago. Top panel: Surveys split between the Main Hawaiian Islands (MHI; unshaded islands) and Northwestern Hawaiian Islands (NWHI). Light gray shading indicates original 50 nautical mile boundary of the Monument (2007), while mid-gray shading indicates the extended 200 nautical mile boundary (2016). Middle panel: MHI surveys around Oahu and Maui-Nui (Maui, Molokai, and Lanai). Dark-gray shaded areas indicate island outlines. Bottom panel: NWHI surveys around Midway Atoll,

Pearl and Hermes Reef, and French Frigate Shoals. Gray shaded areas indicate $\leq 100 \mathrm{~m}$ depths

and MHI generated by a variety of survey methods, with an ancillary focus on size distributions and species encounters.

\subsubsection{Relative abundance metrics}

To compare roving predator densities between NWHI and MHI, we first generated abundance metrics for each survey method. Fish counts from diver SPCs and towed-divers surveys were converted to densities per unit area by dividing counts by the sam- ple areas. For RUVS and BRUVS surveys, we used the MaxN value per 60 min deployment, i.e. the maximum number of that species observed within any video frame during the course of the deployment (Ellis \& Demartini 1995, Willis \& Babcock 2000, Willis et al. 2000).

Roving predator fork-length measurements were also taken for each species at the time of that species' MaxN. All species annotations were reviewed prior to data analysis, with quality control completed by one analyst to maintain consistency across samples (Wilson et al. 2007). 


\subsubsection{Analysis of relative abundance between the NWHI and MHI}

We used a bootstrapping approach to generate relative abundance ratios (AR) between NWHI and MHI, via the boot and boot.ci functions from the boot package in R v.3.3.0 (R Core Team 2016). This was comparable to the technique described by Williams et al. (2011, 2012), Gray et al. (2016), and Williams et al. (2016), which was originally adapted from the analysis of ground fish trawl surveys and particularly well-suited for small sample sizes (Smith 1997). Unlike the direct use of replicates to calculate $95 \%$ confidence intervals produced from parametric methods, we generated pseudo samples of the same size (Henderson 2005) by repeatedly resampling and replacing the original predator abundance data respective to each method and strata (SPC/towed-diver: shallow water only; RUVS/BRUVS: shallow, mesophotic, and all depths pooled). Inferences are therefore made on empirical distributions of survey data rather than assumptions based on distribution form, e.g. presuming data are distributed normally, simulating results as if field surveys were repeated multiple times (Williams et al. 2012).

Here, in each of 1000 iterations, we first generated a mean abundance value for each island from resampled data and converted those to MHI and NWHI mean abundance, weighting each island by the amount of shallow-water hard-bottom habitat at that island (see Table S1 in the Supplement at www.intres.com/articles/suppl/m630p115_supp.pdf). Using this approach, we generated 1000 bootstrapped NWHI: MHI abundance ratios for each combination of fish group, survey method, and depth zone (shallow water or mesophotic) and calculated the mean and $95 \%$ quantile range $[95 \% \mathrm{QR}]$ of those ratios. The $95 \%$ QR covers the middle $95 \%$ of the distribution (i.e. $2.5 \%$ to $97.5 \%$ quantiles) and is analogous to $95 \%$ confidence interval of the NWHI:MHI ratio. We interpreted a $95 \%$ QR of the NWHI:MHI ratio not overlapping 1 as evidence of difference between archipelagic sub-regions, with $95 \% \mathrm{QR}>1$ indicating higher abundance in NWHI, and $95 \% \mathrm{QR}<1$ as evidence of lower abundance in NWHI. We also used the shallow-water habitat area to weight each island's mesophotic densities (which we had for RUVS and BRUVS) because we wanted to be able to meaningfully compare shallow-water and mesophotic NWHI:MHI ratios - without those being affected by different island weightings for shallow and mesophotic data. Finally, we also generated NWHI:MHI 'all depth zones' ratios from BRUVS and RUVS sur- vey data, weighting the shallow water and mesophotic density estimates equally.

\subsubsection{Length-based measurements}

Following standard protocols, SPC and toweddivers visually estimated total length ( $\mathrm{TL}_{\text {; }}$ nose to longest caudal fin lobe) to the nearest $\mathrm{cm}$ of all fishes observed and recorded that information along with abundance estimates (Richards et al. 2011, Ayotte et al. 2015). RUVS and BRUVS surveys gathered fork lengths ( $\mathrm{FL}$; nose to caudal fork) to the nearest $\mathrm{mm}$ at the time of MaxN using EventMeasure-Stereo ${ }^{\mathrm{TM}}$. To align measurement approaches between methods, (1) RUVS and BRUVS FLs were transformed to TLs using conversion parameters taken from FishBase (Froese \& Pauly 2014), and (2) SPC and towed-diver length measurements were converted from $\mathrm{cm}$ to $\mathrm{mm}$ prior to analysis.

One difference between towed-diver surveys and other methods is that, for towed-diver surveys, divers only count fishes with a minimum TL of $50 \mathrm{~cm}$, whereas all sizes are recorded for SPC, RUVS, and BRUVS. As a result, comparisons between other methods and towed-diver data are not made for jacks or for the snapper Aprion virescens. However, Carcharhinus galapagensis and Triaenodon obesus exceed $50 \mathrm{~cm}$ at birth and are frequently encountered in the NWHI (Compagno 1984), allowing for toweddiver length comparisons with other diver and videobased methods in the NWHI.

Notched box plots provide initial indications of differences between length measurements collected by each method, with median notch widths being proportional to interquartile range and inversely proportional to sample size (McGill et al. 1978). While not a formal or strict test, cases where notches do not overlap are indicative of significant differences in median length, independent of assumptions of data normality of distributions or equivalence of variances (Chambers et al. 1983, Harvey et al. 2012).

Non-parametric kernel density estimates (KDEs) were further used to approximate pair-wise comparisons in length frequency distributions between methods in shallow-water strata, based on a null model of no difference between groups and a permutation test $(\mathrm{n}=100000)$ following the approach used by Langlois et al. (2012). KDE tests between species, regions, and methods were constrained to shallowwater subsets recording a minimum of 9 length measurements for RUVS and BRUVS, with SPC and towed-diver surveys consistently collecting larger 
sample sizes across broader length ranges (as a result of more broad-based spatial and temporal sampling). KDE bandwidths were selected using the SheatherJones assignment protocol (Sheather \& Jones 1991) via the function dpik in the package KernSmooth in R v.3.3.0 (Wand \& Jones 1995, Wand \& Ripley 2011, Langlois et al. 2012, R Core Team 2016). Given the sensitivity of length-distribution tests to differences in shape and location, data were also standardized by median and variance to assess shape-only effects (Bowman \& Azzalini 1997, Langlois et al. 2012).
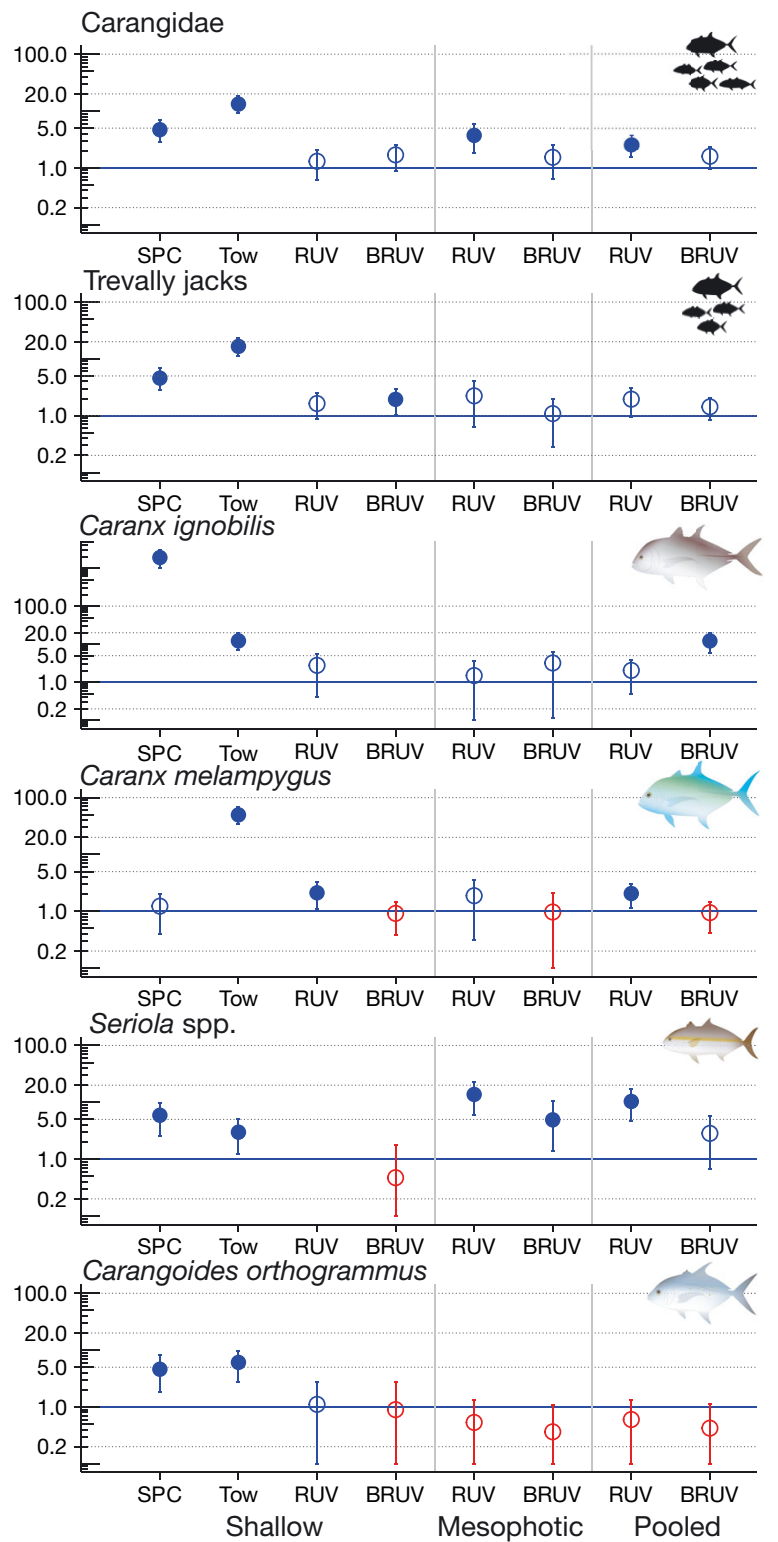

\section{RESULTS}

\subsection{Scales of relative abundance between regions}

All predator NWHI:MHI ratios are shown (for each method) in Fig. 3 and Table S1, with $95 \%$ quantiles presented in brackets and whiskers, respectively (95\%QR, lower $\mathrm{QR}$, and upper $\mathrm{QR}$ ).

Abundances of Carcharhinidae (primarily consisting of reef sharks) and the snapper Aprion virescens were generally higher in the NWHI than the MHI,
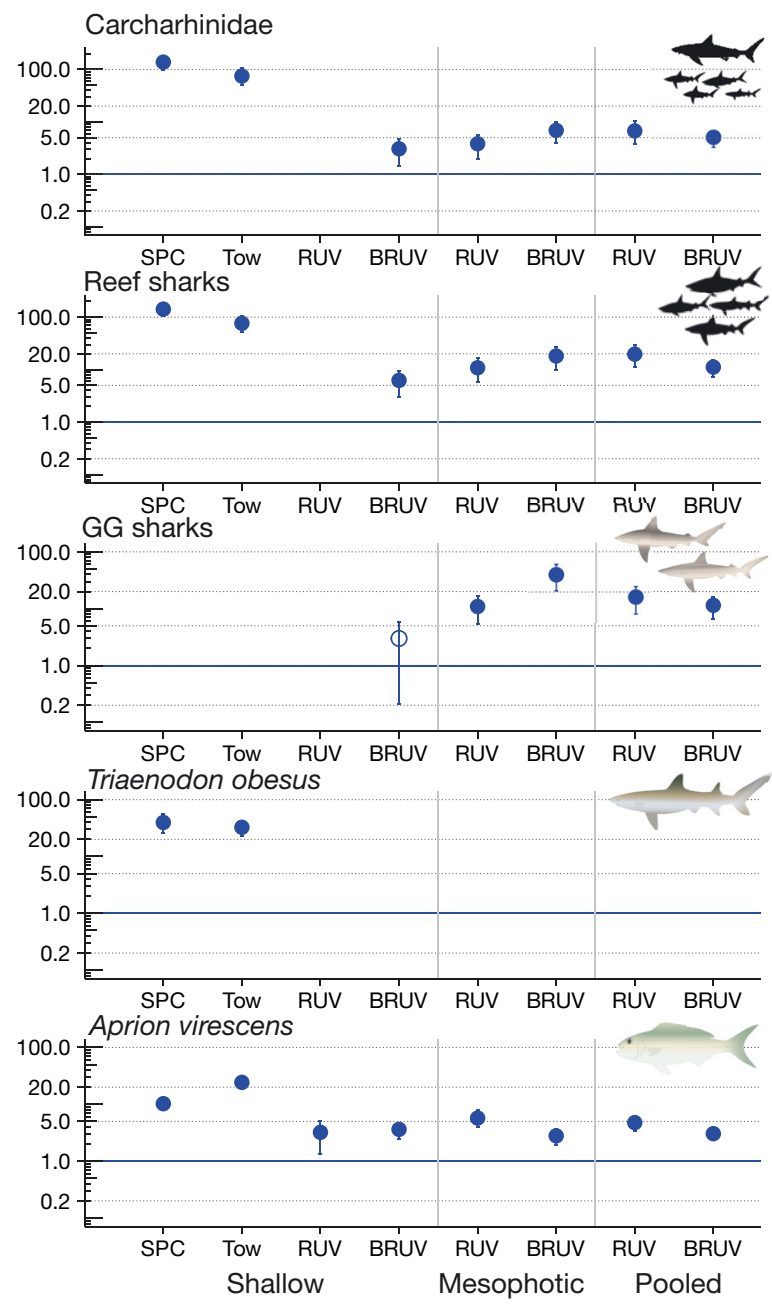

Fig. 3. Differences in roving predator abundances in the Hawaiian Archipelago, presented as the ratio of relative abundances between the NWHI and MHI for each predator group and target species. The blue line represents a ratio of 1 (no differences in abundance between sub-regions). Vertical bars indicate the $95 \%$ quantile range (QR). Red circles: abundance ratio (AR) < 1. Blue circles: AR > 1. Open circles: $95 \%$ QR overlaps 1. Closed circles: 95\%QR does not overlap with 1 . Shallow water (0-30 m): 588 SPC, 243 towed-diver, 65 RUVS, and 39 BRUVS surveys in MHI; 325 SPC, 166 towed-diver, 39 RUVS, and 27 BRUVS surveys in NWHI. Mesophotic (30-100 m): 100 RUVS and 33 BRUVS surveys in MHI; 39 RUVS and 42 BRUVS surveys in NWHI. RUVS and BRUVS results are subdivided into 3 panels. Left: shallow, middle: mesophotic, right: pooled 
irrespective of method used. However, the abundance ratios (AR) tended to be much larger for SPC and towed-diver surveys than for RUVS and BRUVS. A. virescens registered similar NWHI:MHI shallow water abundance ratios for RUVS (mean AR: 3.2, $95 \% \mathrm{QR}: 1.4$ - 5.1) and BRUVS (AR: 3.6, 2.5-4.8), which were 3 to 8 -fold lower than those recorded by SPC (AR: 10.3, 9.0-11.6; 58\% less than towed diver values) or towed-diver surveys (AR: 24.3, 20.3-28.9), with ratios for mesophotic RUV and BRUVS deployments being consistent with those recorded in shallow water. No sharks were recorded during $\mathrm{MHI}$ shallow water RUVS surveys; however, shallow water BRUVS ratios (AR: 6.2, 3.0-9.4) were between 12- and 23-fold lower than for SPC (AR: 142, 105.1179.6) and towed-diver estimates (AR: 76.3, 51.1106.1; $46 \%$ lower than SPC), with mesophotic RUVS (AR: 10.8, 5.7-16.5) and BRUVS (AR: 18.1, 10.0-26.6) also registering lower than diver-based estimates.

In several cases, it was not possible to generate AR values for shark groupings. This frequently occurred where there were considerable count data from NWHI, but zero in the MHI (e.g. SPC, towed-diver, or RUVS sightings of grey reef/Galapagos sharks). However, shallow water BRUVS ratios (AR: 3.0, 0.2-5.9) were $>3$-fold lower than for mesophotic RUVS (AR: $10.9,5.4-16.8)$ and nearly 14 -fold lower than mesophotic BRUVS (AR: 41.1, 21.0-59.8). No T. obesus ARs could be generated for either RUVS or BRUVS as a result of zero sightings in the MHI; however, NWHI:MHI ratios for SPC (AR: 39.7, 25.9-55.1) and towed-diver surveys (AR: 32.6, 23.4-42.3) remained comparable.

The NWHI:MHI predator ratios for Carangidae were largely driven by trevally jacks, and particularly Caranx ignobilis, which was the most abundant species encountered in the NWHI across all methods. Ratios from diver SPC surveys (AR: 1885.1, 1009.73052.2) were the largest AR for any method or response group. The towed-diver mean AR was $>2$ orders of magnitude lower (AR 12.1, 6.9-19.2), followed by RUVS (AR: 2.8, 0.4-5.6). BRUVS did not record any $C$. ignobilis within 0 to $30 \mathrm{~m}$ in the MHI, which precluded shallow-water ratio comparisons with other methods; however, both mesophotic RUVS (AR: 1.5, 0.0-3.6) and mesophotic BRUVS (AR: 3.2, 0.1-6.2) gave values comparable to shallow-water RUVS estimates. Interestingly, when BRUVS estimates were pooled between shallow and mesophotic depths (AR: 12.2, 5.9-19.5), NWHI:MHI ratios were highly similar to those recorded by towed-diver surveys.

Conversely, ratios for Caranx melampygus were relatively closely aligned between shallow-water SPC (AR: 1.2, 0.4-2.0), RUVS (AR 2.1, 1.1-3.2), and
BRUVS (AR: 0.9, 0.4-1.5) along with mesophotic RUVS (AR: 1.9, 0.3-3.5) and BRUVS (AR: 1.0, 0.0-2.1), with assessments being 23- to 55-fold lower than towed-diver estimates (AR: 49.8, 33.9-69.6). AR values for Seriola spp. also showed greater similarity between SPC (AR: 5.9, 2.5-9.7), towed-diver (AR: 3.0, 1.2-5.2), and pooled BRUVS (AR: 2.8, 0.0-5.8). Finally, AR values for Carangoides orthogrammus were comparable between SPCs (AR: 4.6, 1.9-8.3) and towed-diver surveys (AR: 6.1, 2.8-9.5), both of which were 4- to 15-fold higher than for shallow water RUVS (AR: 1.1, 0.0-2.7), shallow water BRUVS (AR: 0.9, 0.0-2.8), mesophotic RUVS (AR: 0.5, 0.01.3), and mesophotic BRUVS (AR: 0.4, 0.0-1.1).

AR values for less-common shark and jack species are given in Table S1.

\subsection{Length-frequencies}

Summarized results are given in Table 1 and Fig. 4. Note that length-based inferences where notches appear outside interquantile ranges (IQRs) should be interpreted with caution, as these may not adequately represent size distributions due to small sample sizes.

Only Caranx melampygus was able to be assessed across the archipelago, with significant differences noted between SPC and RUVS (MHI: $\mathrm{p}<0.01$, NWHI: $\mathrm{p}<0.05)$ and between SPC and BRUVS (MHI: $\mathrm{p}<0.001$, NWHI: $\mathrm{p}<0.05$ ) in both shape and location (Table 2, Fig. 5). Mean SPC lengths were consistently smaller than either RUVS or BRUVS (Figs. 4 \& 5); however, shape tests found no differences between methods, indicating significance was driven between locations of length distributions only (i.e. differences in median length). An exception was noted between SPC and BRUVS being significant for shape tests in the MHI ( $p<0.05$; Table 2, see Fig. S1).

Caranx ignobilis size data showed significant shape and location differences between SPC and BRUVS in the NWHI ( $p<0.01)$ along with significant shape-only tests $(p<0.05)$. This was a likely byproduct of length distributions being unimodal for SPC and bimodal for BRUVS, and the lower overall number of BRUVS measurements being driven by the first mode of smaller fishes. Size estimates from Carcharhinus galapagensis by BRUVS were significantly smaller than those from SPC and towed-diver surveys (Figs. 4 \& 5). Even though shape-only tests found no differences between BRUVS and other methods (Table 2), results should be treated with caution due to the small number of BRUVS samples. 
Table 1. Roving predator mean lengths in the MHI and NWHI by method (SPC: diver stationary point count; RUVS: unbaited remote underwater stereo-video system; BRUVS: baited remote underwater stereo-video system). Lines separate measurements made in shallow (first 3 rows) versus mesophotic depths (RUVS/BRUVS only). Note: due to small sample sizes, Caranx ignobilis measurement comparisons were only calculated for the NWHI. Values are displayed as mean \pm SE. ' - ' indicates no recorded length-based estimates

\begin{tabular}{|c|c|c|c|c|c|}
\hline \multirow{2}{*}{ Species } & \multirow{2}{*}{ Method } & \multicolumn{2}{|c|}{ Main Hawaiian Islands } & \multicolumn{2}{|c|}{ Northwestern Hawaiian Islands } \\
\hline & & $\begin{array}{l}\text { Mean length } \\
\quad( \pm \mathrm{SE})\end{array}$ & $\begin{array}{l}\text { Measurements } \\
(\mathrm{N})\end{array}$ & $\begin{array}{l}\text { Mean length } \\
\quad( \pm \mathrm{SE})\end{array}$ & $\begin{array}{l}\text { Measurements } \\
\text { (N) }\end{array}$ \\
\hline \multirow[t]{5}{*}{ Apion virescens } & SPC & $415.1 \pm 11.2$ & 132 & $554.4 \pm 8.0$ & 406 \\
\hline & RUVS & $449.5 \pm 112.5$ & 3 & $621.3 \pm 50.0$ & 9 \\
\hline & BRUVS & $490.5 \pm 123.8$ & 6 & $637.8 \pm 29.8$ & 21 \\
\hline & RUVS (mesophotic) & $308.0 \pm 0.0$ & 1 & $607.1 \pm 31.3$ & 34 \\
\hline & BRUVS (mesophotic) & $529.5 \pm 72.9$ & 6 & $651.6 \pm 14.0$ & 25 \\
\hline \multirow[t]{5}{*}{ Caranx melampygus } & SPC & $254.7 \pm 5.4$ & 185 & $461.9 \pm 7.2$ & 215 \\
\hline & RUVS & $318.2 \pm 19.2$ & 20 & $528.6 \pm 28.2$ & 21 \\
\hline & BRUVS & $335.2 \pm 22.4$ & 26 & $526.5 \pm 45.3$ & 12 \\
\hline & RUVS (mesophotic) & $484.8 \pm 59.6$ & 3 & $466.8 \pm 21.5$ & 21 \\
\hline & BRUVS (mesophotic) & $454.4 \pm 34$ & 7 & $465.8 \pm 35.7$ & 8 \\
\hline \multirow[t]{5}{*}{ Caranx ignobilis } & SPC & $110 \pm 0.0$ & 1 & $815.1 \pm 10.3$ & 319 \\
\hline & RUVS & $337.6 \pm 0.9$ & 2 & $860.7 \pm 22.9$ & 7 \\
\hline & BRUVS & - & 0 & $828.3 \pm 41.8$ & 27 \\
\hline & RUVS (mesophotic) & $572.4 \pm 0.0$ & 1 & $983.0 \pm 92.7$ & 2 \\
\hline & BRUVS (mesophotic) & $740.0 \pm 17.0$ & 4 & $1017.8 \pm 26.9$ & 6 \\
\hline \multirow[t]{6}{*}{ Carcharhinus galapagensis } & SPC & - & - & $1151.1 \pm 34.8$ & 68 \\
\hline & Towed-diver & - & - & $1087.8 \pm 35.9$ & 41 \\
\hline & RUVS & - & - & $980.2 \pm 4.1$ & 2 \\
\hline & BRUVS & - & - & $934.1 \pm 15.2$ & 9 \\
\hline & RUVS (mesophotic) & - & - & $1220.1 \pm 81.2$ & 9 \\
\hline & BRUVS (mesophotic) & - & - & $1280.7 \pm 44.5$ & 11 \\
\hline \multirow[t]{6}{*}{ Triaenodon obesus } & SPC & - & - & $1111.3 \pm 27.8$ & 43 \\
\hline & Towed-diver & - & - & $1387.2 \pm 37.5$ & 43 \\
\hline & RUVS & - & - & $1081.5 \pm 56.7$ & 4 \\
\hline & BRUVS & - & - & $1065.5 \pm 61.9$ & 5 \\
\hline & RUVS (mesophotic) & - & - & $1064.5 \pm 38.6$ & 3 \\
\hline & BRUVS (mesophotic) & - & - & $1196.4 \pm 24.9$ & 10 \\
\hline
\end{tabular}

Table 2. Outputs of kernel density tests of differences between pairs of fish length-frequency distributions sampled by SPC, towed-diver RUVS, and BRUVS (shallow-water only). Significance tests on raw data test for differences in location and shape of length-frequency distributions. Bold font indicates significance at $\mathrm{p}<0.05$. Tests on standardized data provide a test of shape only. '-' indicates insufficient $(\mathrm{N}<9)$ or absent length-based estimates required to conduct kernel density tests

\begin{tabular}{|c|c|c|c|c|c|}
\hline \multirow[t]{2}{*}{ Species } & \multirow{2}{*}{$\begin{array}{l}\text { Method } \\
\text { comparison }\end{array}$} & \multicolumn{2}{|c|}{ Main Hawaiian Islands } & \multicolumn{2}{|c|}{ Northwestern Hawaiian Islands } \\
\hline & & $\begin{array}{c}\text { Shape } \\
\text { and Location }\end{array}$ & $\begin{array}{l}\text { Shape } \\
\text { only }\end{array}$ & $\begin{array}{c}\text { Shape } \\
\text { and Location }\end{array}$ & $\begin{array}{l}\text { Shape } \\
\text { only }\end{array}$ \\
\hline \multirow[t]{3}{*}{ Aprion virescens } & SPC vs. RUVS & - & - & 0.276 & 0.202 \\
\hline & SPC vs. BRUVS & - & - & $<0.001$ & 0.292 \\
\hline & RUVS vs. BRUVS & - & - & 0.756 & 0.872 \\
\hline \multirow[t]{3}{*}{ Caranx melampygus } & SPC vs. RUVS & 0.008 & 0.834 & 0.036 & 0.446 \\
\hline & SPC vs. BRUVS & $<0.001$ & $<0.04$ & 0.028 & 0.132 \\
\hline & RUVS vs. BRUVS & 0.170 & 0.140 & 0.518 & 0.440 \\
\hline Caranx ignobilis & SPC vs. BRUVS & - & - & 0.004 & 0.020 \\
\hline \multirow[t]{3}{*}{ Carcharhinus galapagensis } & SPC vs. Tow & - & - & 0.240 & 0.018 \\
\hline & SPC vs. BRUVS & - & - & $<0.001$ & 0.462 \\
\hline & Tow vs. BRUVS & - & - & $<0.001$ & 0.516 \\
\hline Triaenodon obesus & SPC vs. Tow & - & - & $<0.001$ & 0.292 \\
\hline
\end{tabular}



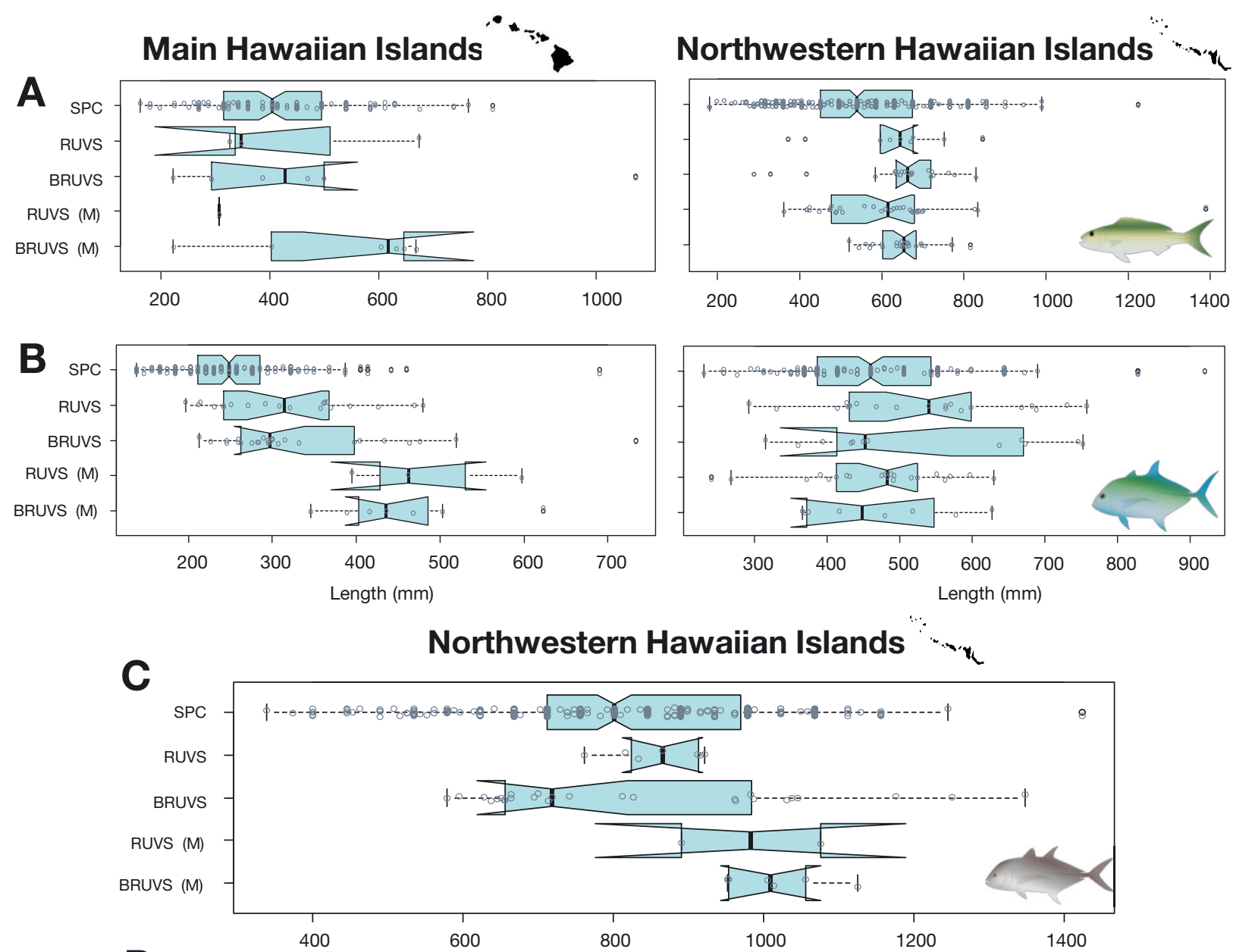

D

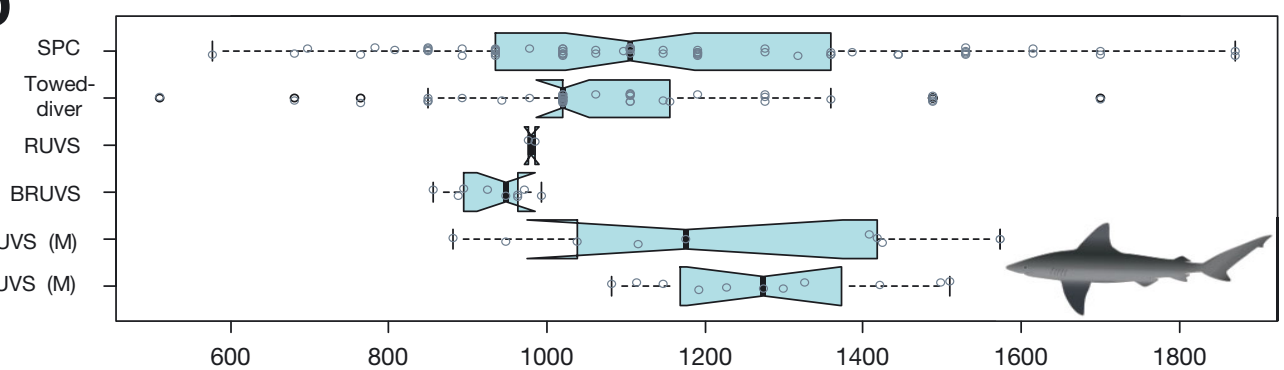

E

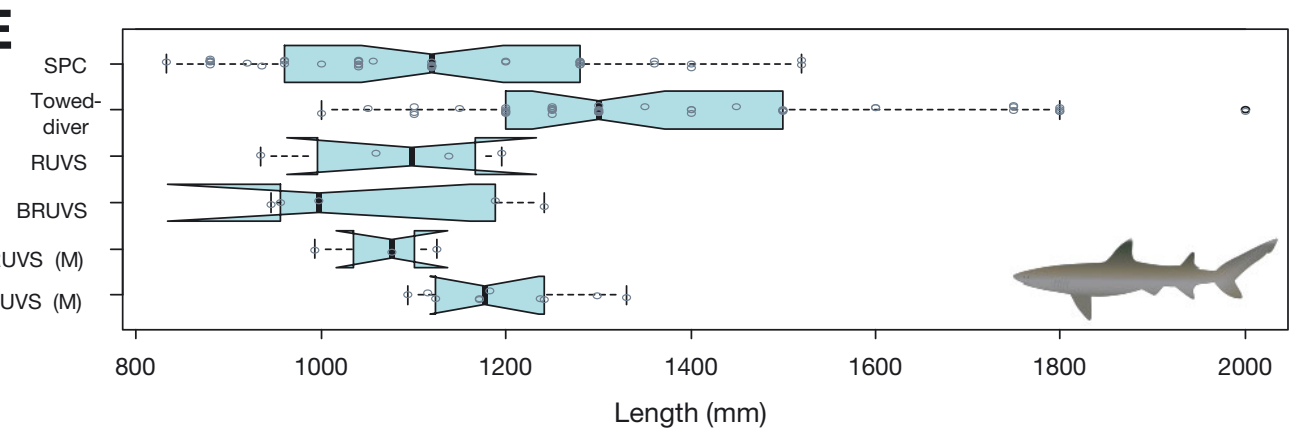

Fig. 4. Notched Tukey boxplots of median lengths (length of caudal fork, mm). Bold vertical line indicates the median, boxes indicate the $25^{\text {th }}$ and $75^{\text {th }}$ percentiles, and whiskers indicate $1.5 \times$ interquartile ranges (IQR). Boxplot notches represent $95 \%$ confidence intervals of median (median $\pm 1.57 \times \mathrm{IQR} / \mathrm{n}^{0.5}$ ). (A) Aprion virescens and (B) Caranx melampygus sampled by SPC, RUVS, and BRUVS (shallow and mesophotic (M) for both video-sampling methods) in the MHI and NWHI. Additional NWHIinclusive comparisons were conducted for (C) Caranx ignobilis, (D) Carcharhinus galapagensis, and (E) Triaenodon obesus. 


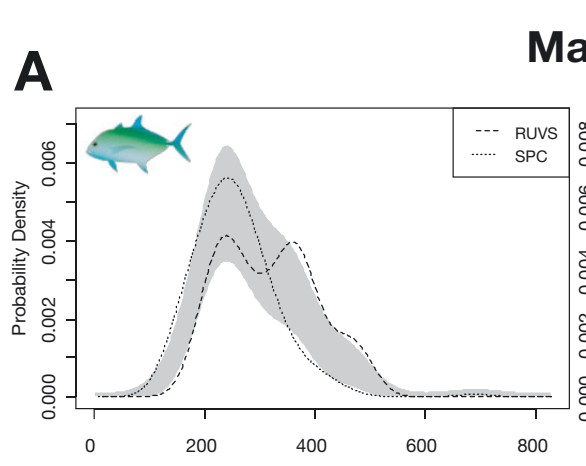

\section{Main Hawaiian Islands}
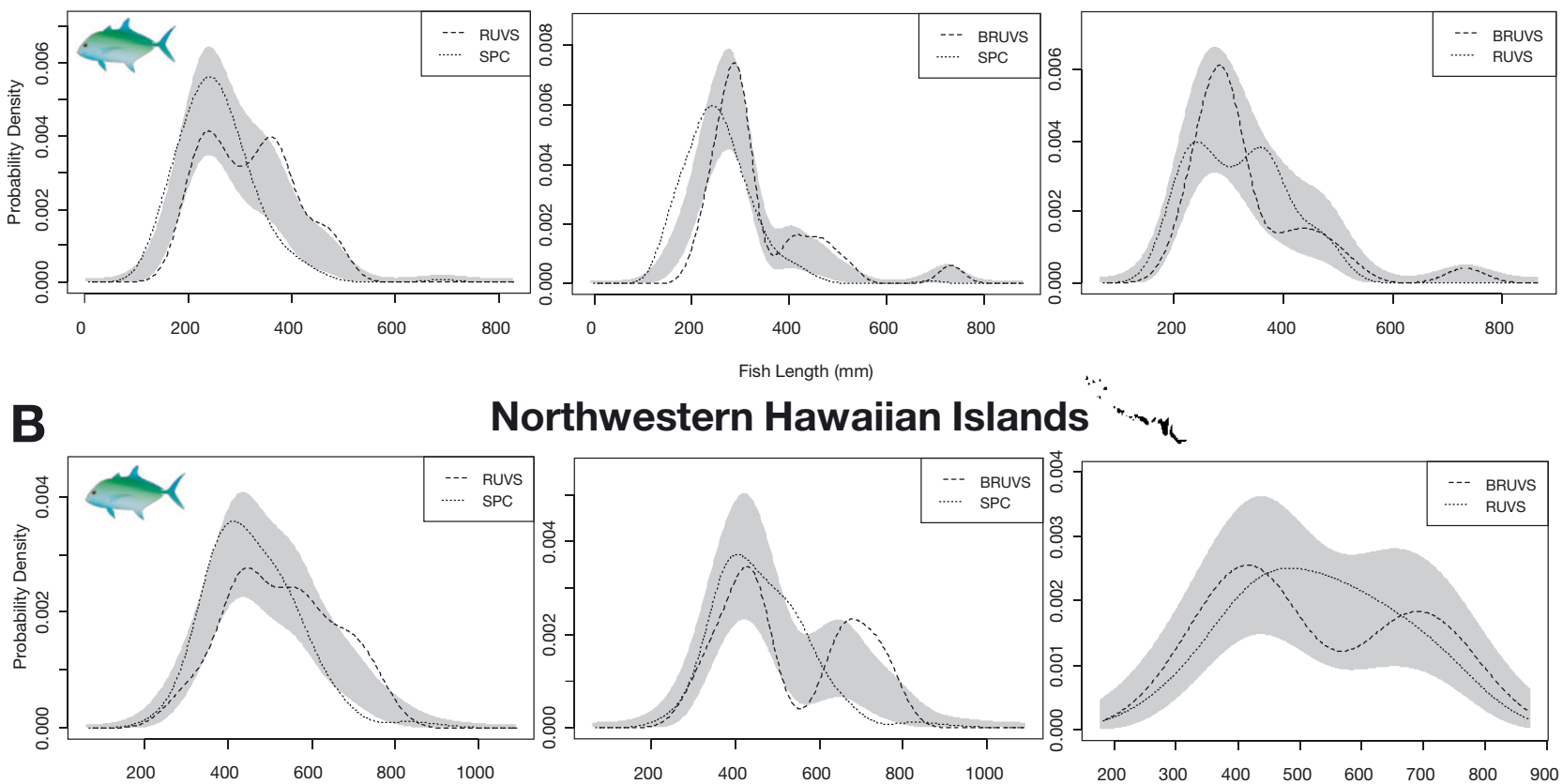

Northwestern Hawaiian Islands $\cdots, x$
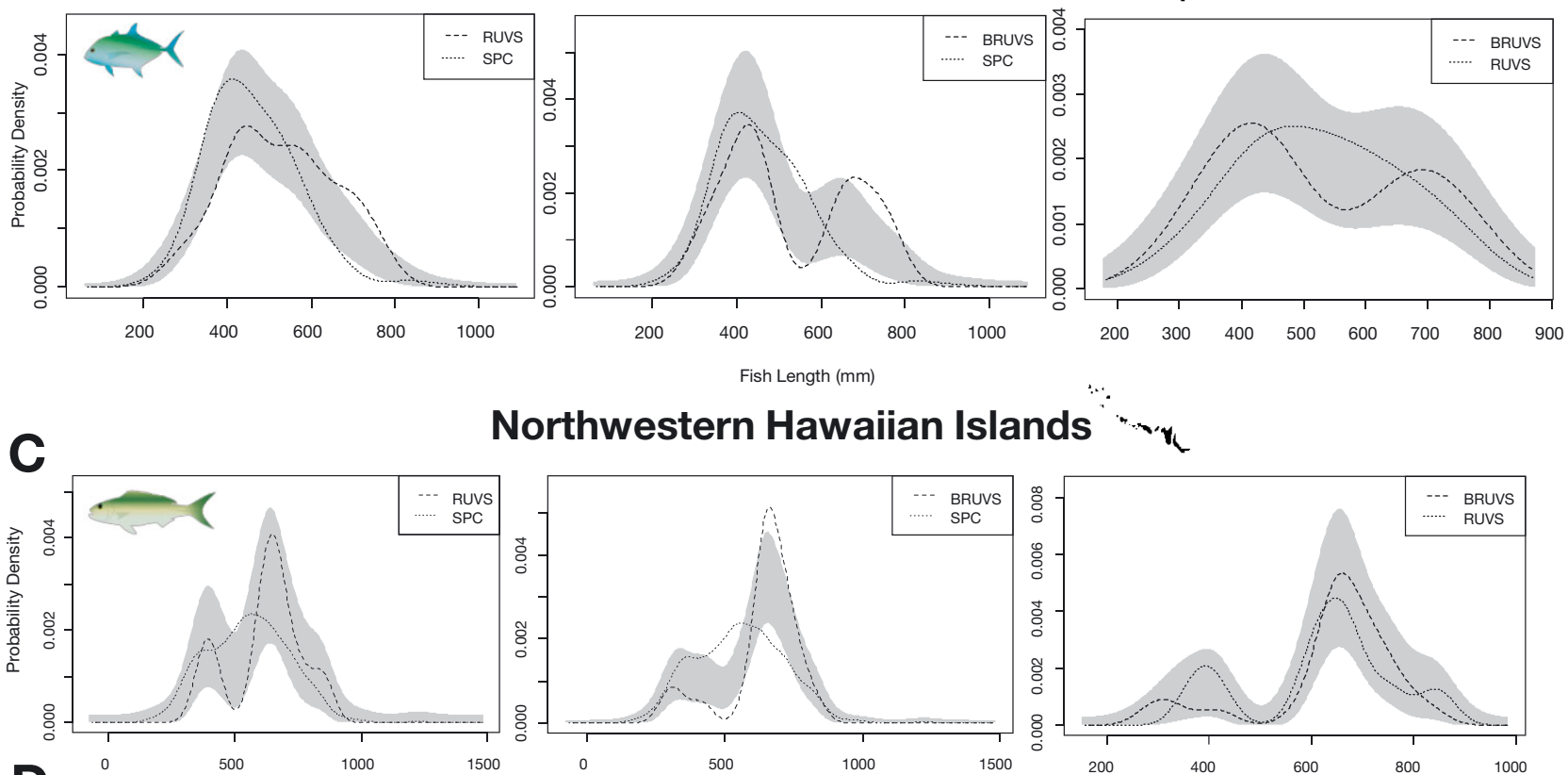

D
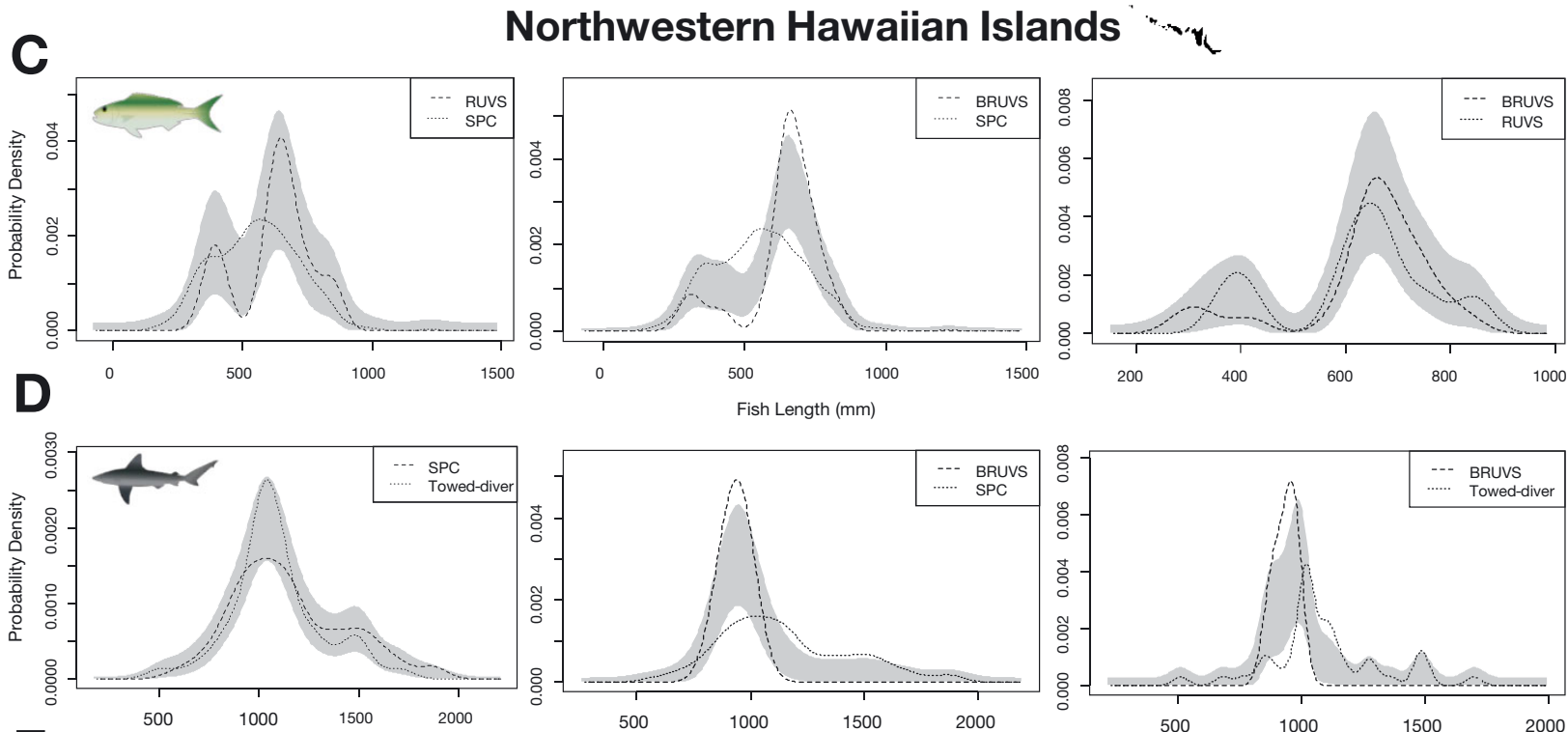

Fish Length $(\mathrm{mm})$
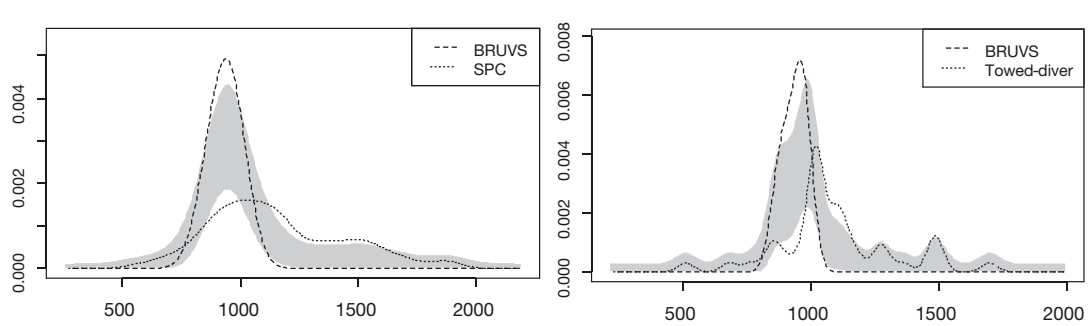

$\mathbf{E}$

Fish Length $(\mathrm{mm})$
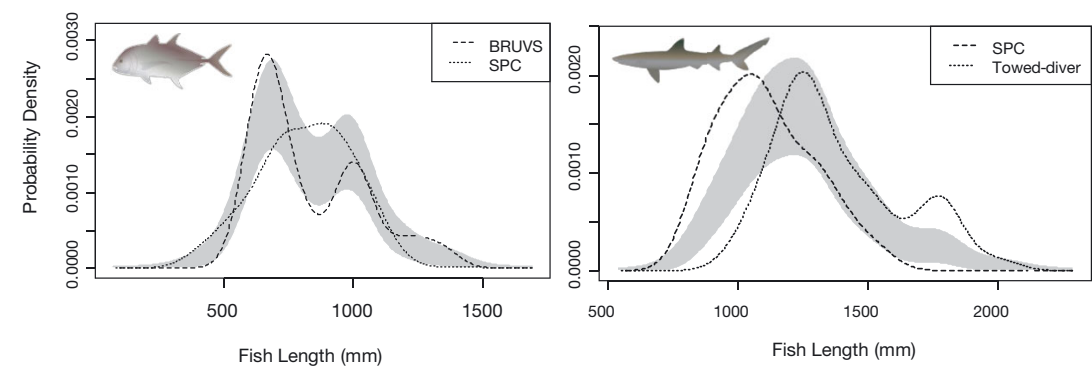

Fig. 5. Comparison of kernel density estimate (KDE) probabilities using mean bandwidths for (A,B) Caranx melampygus in the MHI and the NWHI, and (C) Aprion virescens, (D) Carcharhinus galapagensis, (E) Caranx ignobilis, and (F) Triaenodon obesus in the NWHI between the length frequency data of paired methods. Tests for differences in location and shape of length frequency raw data. Grey bands indicate 1 standard error to either side of the null model 
In contrast, significant shape test $(\mathrm{p}<0.02$; no difference in tests for shape and location) results of comparisons between SPC and towed-diver surveys indicate that each method was either sampling different portions of the population (with the average towed-diver length estimates being 5.6\% smaller than diver SPCs) or one method was possibly (SPC) over- or (tow) under-sizing Carcharhinus galapagensis lengths. Finally, mean length estimates for Triaenodon obesus were $\sim 20 \%$ smaller for SPC than for towed-divers $(\mathrm{p}<0.001$ for shape and location; no differences for shape-only tests).

\subsection{Species specific to visual assessment type}

Several species were sighted exclusively on either diver or video sampling. Among Carangidae, these included Caranx sexfasciatus (SPC and tow only, NWHI), Elagatis bipinnulata (SPC and tow only, MHI and NWHI), Seriola lalandi (RUVS and BRUVS only, NWHI mesophotic depths only), and Gnathanodon speciosus (BRUVS only, MHI and NWHI).

A number of shark species were also recorded solely during video sampling. These included Galeocerdo cuvier (RUVS and BRUVS) and Carcharhinus plumbeus (RUVS and BRUVS, mesophotic only). In addition, a single sighting of Carcharhinus melanopterus was recorded by a shallow-water BRUVS in the MHI. Finally, Carcharhinus limbatus was noted during RUVS and BRUVS recordings in the MHI, along with a single scalloped hammerhead Sphyrna lewini (shallow-water RUVS only), which all occurred outside of $1 \mathrm{~h}$ sampling periods (i.e. during camera station descents or following the conclusion of sampling).

\section{DISCUSSION}

This research expands on other underwater census studies in Hawaii, including comparisons between coral reef fish SPC surveys on open-circuit SCUBA versus closed circuit rebreathers (Gray et al. 2016). Here, we conducted the first large-scale predator comparison study between diver SPC, towed-diver, RUVS, and BRUVS, with the primary goal of appraising relative abundances between the NWHI and MHI. While the results remained broadly consistent, in that many predator groups and individually assessed species were much more common in the NWHI than in the MHI, there were also substantial discrepancies depending on the assessment ap- proach used. These variations highlight the common challenges encountered by research programs examining large-bodied roving predator populations, i.e. their inherent patchiness (especially in areas prone to fishing pressure), high general degrees of mobility, variable and species-dependent behavioral responses to divers between regions, and wide-ranging horizontal and vertical distributions (Wetherbee et al. 1997, Meyer et al. 2007b, 2009b, Vaudo et al. 2014, Papastamatiou et al. 2015). Seasonal, diurnal, and lunar drivers may also influence predator movements, providing additional challenges to obtaining accurate predator abundance estimates (Merson \& Pratt 2001, Speed et al. 2011, Whitney et al. 2012, Vianna et al. 2013).

It was noteworthy that NWHI:MHI abundance ratios derived from RUVS and BRUVS surveys (Fig. 3) were similar for several groups (e.g. all Carcharhinidae for pooled depths) and species (e.g. Aprion virescens and Carangoides orthogrammus in shallow, mesophotic, and pooled depths). Although BRUVS recorded consistently higher predator encounter rates than RUVS for these examples in both regions, it appears that increased encounter rates (due to baiting effects) were generally of similar scale in each region. These results may therefore reduce some of the concerns surrounding the potential for baiting biases and consequent inflation of predator density estimates due to fish being drawn from outside of visible sampling areas. However, as neither BRUVS nor RUVS effectively sampled some of the species encountered (albeit rarely) in the MHI (e.g. Triaenodon obesus), and because there were still some differences between BRUVS and RUVS abundance ratios (e.g. Galapagos sharks in mesophotic areas), there is still a need for specifically designed, rigorous methods comparison studies.

Although towed-diver abundance ratios had a tendency to be higher than RUVS or BRUVS in shallow water, they were surprisingly consistent for Caranx ignobilis and Seriola spp. when compared with pooled (combined shallow and mesphotic) data from RUVS and/or BRUVS. One possible explanation is predators were being drawn into towed-diver sampling swaths from deeper depths, where some species (e.g. Seriola spp.) are known to occur in greater numbers (Tamaru et al. 2016). Towed-divers also observed occasional changes in predator behavior, particularly in high-density areas where, at times, aggregations of predators may trail divers during surveys (J. Asher pers. obs.; Fig. 6), paralleling foraging activities noted between top-level roving predators and Hawaiian monk seals Monachus schauins- 

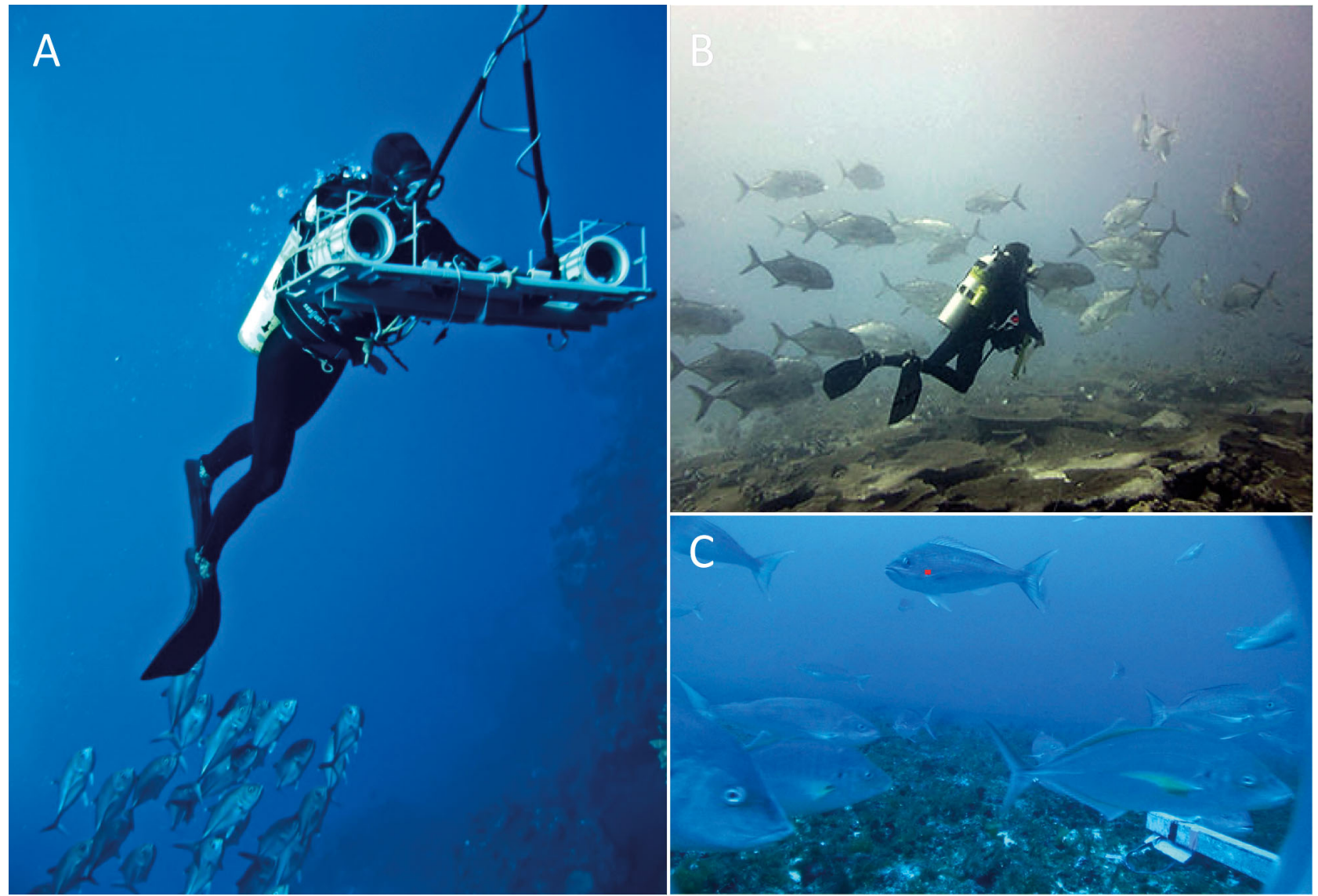

Fig. 6. Examples of predator attraction behaviors. (A) School of Caranx sexfasciatus trailing towed diver. Photograph by J. Asher. (B) School of Caranx ignobilis surrounding SPC diver. Photograph by NOAA. (C) Mixed school of Seriola spp., Pseudocaranx cheilio, and Pristipomoides filamentosus surrounding a RUVS. Photograph by J. Asher. Red dots: identification points used during BRUV and RUV image annotations

landi (Parrish et al. 2008). While groups of predators trailing towed divers are not recorded during surveys, those aggregations do indicate that certain species of roving predators are being attracted to divers and therefore drawn from other habitats (e.g. potentially deeper water), which may (at least partially) account for the high NWHI:MHI ratios for sharks and other jack species (e.g. pooled trevallies, Caranx melampygus, Carangoides orthogrammus).

It appears that, in some circumstances, towed-diver surveys can also be subject to negatively biased counts (i.e. underestimates). For example, densities from shallow-water towed-diver surveys were between 200 and $900 \%$ lower than those from timedswim surveys, BRUVS, and audible stationary counts in Australia (Rizzari et al. 2014). It is possible that noise or other disturbance caused by a moving small boat may drive sharks and potentially other roving predators out of the immediate path of towed divers, particularly in shallow water. Certainly, vessel noise can either attract, repulse, or alter roving predator behaviors in other ways or have no measurable effects (Meyer et al. 2009b, Fitzpatrick et al. 2011, Smith et al. 2016, Chapuis et al. 2019); however, the only study we are aware of in the NWHI found no impact acoustic of playback of motorized vessels on Galapagos shark-monk seal predation rates (Gobush \& Farry 2012).

Diver SPC surveys are, in several ways, well-suited to sampling of demersal, site-attached species or those mobile species that are relatively unaffected by the presence of divers. However, predator abundance inflation is a concern, particularly in remote locations where predators are abundant and where they are likely to be attracted to the relative novelty of divers' presence. Conversely, small-scale diver surveys may underrepresent mobile predator abundance in populated regions, particularly in areas where species can become averse to divers as a result of elevated fishing pressures (Januchowski-Hartley 
et al. 2012, Lindfield et al. 2014, Goetze et al. 2015, Gray et al. 2016). Of the predatory species examined, C. ignobilis had the widest abundance discrepancies in abundance ratios between methods, with $>2$ orders of magnitude separating diver SPC censuses to towed-diver, RUVS, and BRUVS surveys. For this species, it seems very likely that divers overestimate densities in small area surveys, particularly for noninstantaneous methods (Friedlander \& DeMartini 2002, Sandin et al. 2008b, Ward-Paige et al. 2010a, Richards et al. 2011, Nadon et al. 2012). As the most commonly encountered jack species with the highest overall predator biomass in the NWHI, this species is not observed in comparable numbers anywhere else in Hawaii or the US Pacific Territories. Overall, the very high NWHI:MHI SPC ratios are probably indicative of both strong SPC attraction effects inflating density estimates in the NWHI (Fig. 6), coupled with real low abundance in the MHI, which was evident across all survey methods and potentially indicative of depleted populations there (Friedlander \& DeMartini 2002, Dale et al. 2010, Santos et al. 2011, Nadon 2017). While towed-diver surveys are not immune to overinflating predator counts, they cover considerably larger areas, with divers moving at $\sim 45 \mathrm{~m} \mathrm{~min}^{-1}$, in contrast to divers conducting SPC and belt transects, who are stationary or moving slowly, which likely reduces the impacts of predator aggregation and attraction on towed-diver surveys (Richards et al. 2011, Nadon et al. 2012). However, towed-diver abundance ratios were still considerably higher than for shallow-water RUVS and BRUVS, e.g. for pooled trevally jacks and C. melampygus, and the possibility of inflated predator abundance ratios in the NWHI remains a concern.

RUVS and BRUVS retain several benefits over diver-based censuses. Both show promise as fisheryindependent methods for sampling assemblages and large-bodied predator species beyond $30 \mathrm{~m}$ but can be used in both shallow and deep-water coral reef environments. Important considerations for using BRUVS include unknown bait attraction effects, as plume areas remain challenging to quantify. Other potential sources of variability include the bait type, varying responses to bait between species, density of fish that can be observed within the visible sampling areas in front of cameras, and the potential for competitive exclusion of some species by others (Willis \& Babcock 2000, Bailey \& Priede 2002, Stobart et al. 2007, Dorman et al. 2012, Ghazilou et al. 2016, Walsh et al. 2016).

Ancillary to possible baiting effects associated with underwater video sampling, locations with higher baited angling or shore-based creel fishing have been linked to feeding hesitation among potentially capture-susceptible species, i.e. roving predators (Colefax et al. 2016), with some studies suggestive of decreased likelihood of recapture following catchand-release (Fedele 2017). However, we are unaware of any existing BRUVS studies comparing bait avoidance or hesitancy responses, changes to abundance measures, and/or alterations to target species or predator distributions as a result of line-based, baited fishing pressures along populated areas proximal to baited underwater survey sites.

The use of RUVS reduces concerns associated with baiting, i.e. attracting fishes outside of visible sampling areas or from adjacent habitats, resulting in biased estimates of abundance, biomass, and/or species richness (Bradley et al. 2017a, Sheaves et al. 2016). RUVS may also be better suited for specialist research projects where baiting would confound results interpretation, e.g. monitoring predator encounters at aquaculture sites (Loiseau et al. 2016). Conversely, RUVS abundance estimates are typically subject to higher spatial and temporal variability than baited camera systems, due to lower encounter rates, potentially in combination with greater importance of small- to medium-scale differences in oceanography or habitat that are not dampened by the mitigating effects of bait attractants (Watson et al. 2005). Lower RUVS encounter rates are an especially important consideration in areas where predator populations are patchy and/or rarely encountered, e.g. in areas where they are depleted by fishing (Harvey et al. 2007). RUVS are also not completely shielded from additional sampling biases, particularly in light of 'structural attraction' effects whereby predators may be drawn to camera stations deployed in low-complexity, featureless plains (e.g. sand flats or low-lying, consolidated pavement flats; Fig. 5C). Finally, both RUVS and BRUVS may be vulnerable to count saturation in areas where predator densities are extremely high (Schobernd et al. 2014, Bacheler \& Shertzer 2015).

There were several inconsistencies between predator length distributions generated from different methods. For example, mean predator size and length distributions for C. melampygus (and most other species) were consistently smaller from diver SPC. If this represents a real weakness of SPC-e.g. that diver surveys underrepresent large individuals - then population assessments generated from small-scale diver data may overestimate scales of depletion. In addition, with mean lengths falling below the $50 \mathrm{~cm}$ measurement threshold, the majority 
of C. melampygus in the MHI and to a lesser extent $A$. virescens in the NWHI also fall outside of the current detection range for towed-diver surveys, which may constrain population estimates, particularly when examining predators in depleted areas or in areas of high fishing pressure (Nadon et al. 2015, Nadon 2017). Of additional interest were sightings of much larger whitetip reef sharks T. obesus by toweddivers in comparison with diver SPCs. This may indicate another source of systemic sizing bias among methods, which in this case, relate to sighting distances and detectability, as SPC divers can observe partially hidden, resting whitetip reef sharks more clearly than towed-divers moving through the water column (Whitney et al. 2007, Barnett et al. 2012). Finally, the detection of larger and fewer jacks by RUVS and/or BRUVS (e.g. C. melampygus and C. ignobilis) versus those collected by SPC and toweddivers indicates the potential for intraspecific competition biases. Specifically, larger fishes attracted by the structural components of the RUVS/BRUVS themselves (e.g. in low-complexity environments; Fig. 5C) or by baited attractants (in the case of BRUVS) may competitively exclude smaller, subordinate fish from the limited fields of view.

Several predatory species were sighted exclusively by either video or diver-based methods. Two schooling Carangidae (Elagatis bipinnulata and Caranx sexfasciatus) were absent from RUVS and BRUVS surveys in shallow water but were recorded during SPC and/or towed-diver surveys. These represented rare sightings of primarily coastal pelagic species moving closer to shore (in the case of E. bipinnulata) or intermittent, inherently patchy distributions ( $C$. sexfasciatus) of species being missed by the more spatially and temporally limited video surveys used in this study (Schwarz 2004, Schroeder \& Parrish 2006, Froese \& Pauly 2014). In contrast, RUVS and BRUVS surveys recorded several Galeocerdo cuvier and Carcharhinus plumbeus (both species in the MHI and NWHI), as well as jack species (e.g. Seriola lalandi) not recorded by divers either during toweddiver or SPC surveys (Fig. 7), with the latter 2 species encountered exclusively in mesophotic surveys. Also, the absence of Galeocerdo cuvier from diver surveys, despite the fact that they were recorded in shallow water by both RUVS and BRUVS, together with the considerably greater number of those diver surveys, is suggestive of diver avoidance by that species (Dale et al. 2011). An alternative data source for roving predator populations comes from longline catch surveys, which, like BRUVS and RUVS, are able to survey reef-associated predatory species that tend to be poorly represented in diver censuses. For example, examination of MHI longline CPUE data collected by Hawaiian shark control programs between 1959 and 1976 showed that, although grey reef sharks and Galapagos sharks were rarely caught around the more populated parts of the MHI, tiger sharks $G$. cuvier and sandbar sharks C. plumbeus were regularly hooked (Papastamatiou et al. 2006, Dale et al. 2011). Seriola rivoliana were also observed during both RUVS and BRUVS (primarily in mesophotic depths) but not during any diver surveys. However, as $S$. rivoliana is very similar in appearance to Seriola dumerili and often forms mixed schools, it is likely that SPC and towed-diver observers recorded all Seriola spp. as S. dumerili. Finally, as mark-andrecapture and long-term tracking studies indicate that large portions of populations of several roving predator species (e.g. A. virescens, C. ignobilis, and C. galapagensis) are more abundant in mesophotic depths, it is clear that complimentary methods, capable of sampling deeper habitats, are needed to fully assess the status of roving predator populations (Meyer et al. 2007a, Nakamura et al. 2011, Pickard 2013, Papastamatiou et al. 2015). It is important to note that while tracking and mark-and-recapture techniques represent viable and valuable methods to assess roving predator populations, they are not a panacea because they remain susceptible to their own information gaps, e.g. potential omission of inter-island predator movements (Tagawa \& Tam 2006, Meyer et al. 2007a, Nadon 2017).

The evidence used to support so called 'inverted biomass' or trophic pyramids, in which greatest biomass occurs at the top of the food chain, comes primarily from diver-based (belt-transect) underwater visual surveys at remote atolls and islands (Newman et al. 2006, DeMartini et al. 2008, Sandin et al. 2008b, Salinas de León et al. 2016, Bradley et al. 2017b). Toplevel predator systems can be sustained through subsidiary inputs, i.e. seasonal or episodic immigration of schooling mobile invertivores, planktivores, and lower-level functional groups, or during spawning events (Polis et al. 1997, Mourier et al. 2016, Trebilco et al. 2016). Lastly, inverted pyramids may be sustained in areas hosting habitats with complex or extensive hiding (refuge) spaces for prey species (Wang et al. 2009). Although our study does not attempt to determine the trophic structure of reef fishes in the Hawaiian archipelago, our results corroborate other studies which have suggested that other than in circumstances described above, these inverted trophic structures are likely to be an artifact of behavioral bias, e.g. attraction of roving predators to divers in re- 


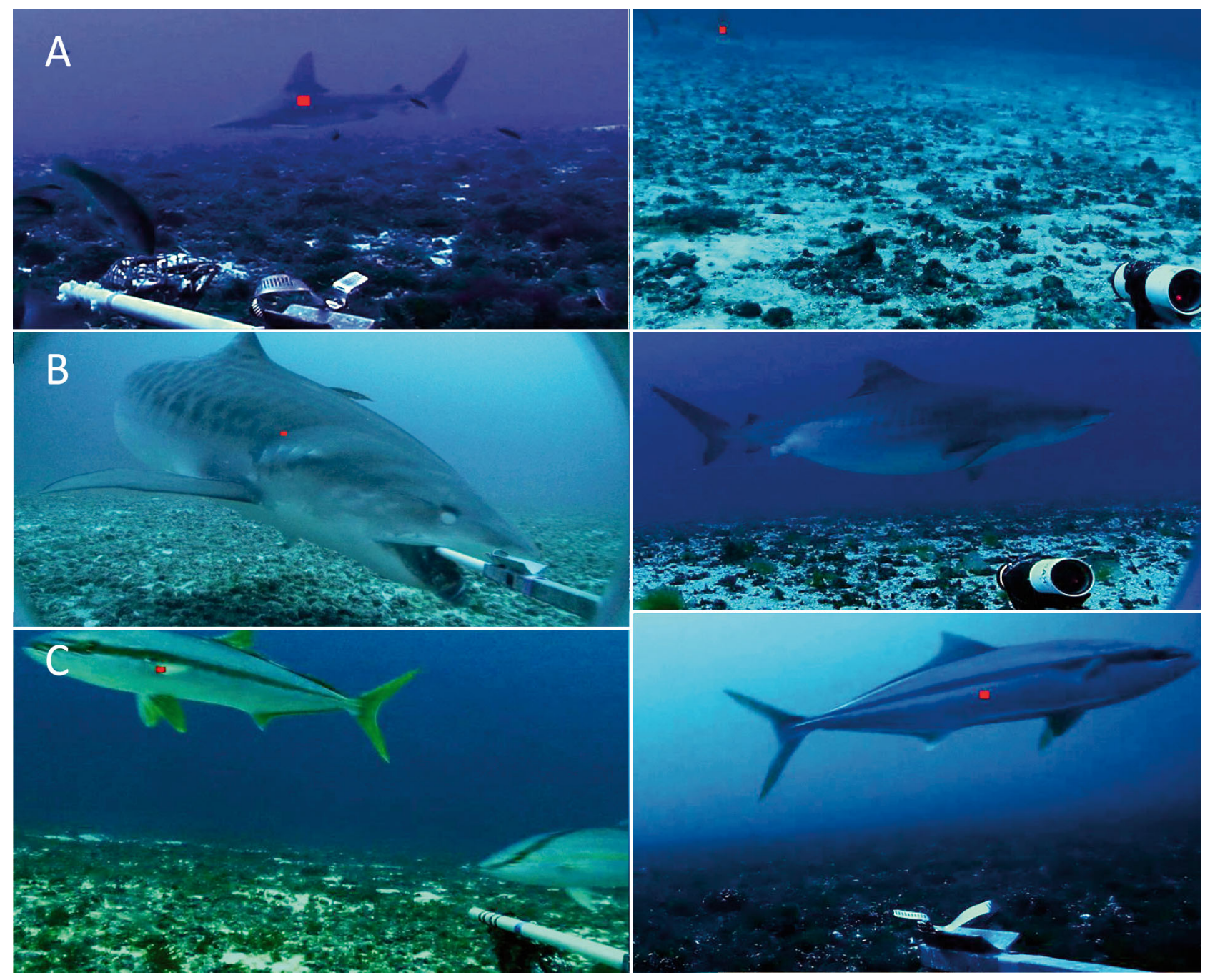

Fig. 7. Species encountered solely during stereo-video sampling, recorded by both RUVS (right panels) and BRUVS (left panels). (A) Carcharhinus plumbeus, (B) Galeocerdo cuvier, (C) Seriola lalandi. Note that Carcharhinus plumbeus and Seriola lalandi were recorded in mesophotic depths only. Red dots: identification points used during BRUV and RUV image annotations

mote areas, combined with a methodological bias for overcounting mobile species in small sampling areas (Friedlander \& DeMartini 2002, Sandin et al. 2008b, Ward-Paige et al. 2010a, Williams et al. 2011, Nadon et al. 2012). However, consistently higher toweddiver abundance ratios suggest that in areas hosting high-density predator populations, diver attraction and inflated diver-based predator estimates might be occurring as a result of counting biases. These could be linked to asymmetric predator 'over counts' due to increased predator mobility (versus slower, lessactive trophic groups) seen with non-instantaneous underwater visual censuses or to diver attraction as previously described with SPC and belt-transects (Sandin et al. 2008a, Ward-Paige et al. 2010a, Dickens et al. 2011, Nadon et al. 2012). Lastly, sepa- rate mark-and-recapture surveys of grey reef sharks similarly suggests predator biomass at Palmyra atoll may be inflated by up to $56 \%$, which would shift pyramid structure to being top-heavy, but not inverted (Bradley et al. 2017). Given the uncertainties in predator population estimates depending on the type of method used, continued assessments of predator populations through the use and evaluation of multiple methods remain paramount.

For each method, pooling multiple survey years was necessary to obtain sufficient samples to compare between the MHI and NWHI. As such, there were some differences in the time of year and years surveyed among methods that were an unavoidable byproduct of cruise schedules and the availability of resources and personnel to conduct different sur- 
veys. While we covered a broad geographic swath in a spatially comprehensive approach across multiple depth strata, it is worth considering potential biases associated with differences in abundance among different times or seasons of the year.

In the MHI, large-bodied predators are patchily distributed and generally uncommon (in comparison to the NWHI); however, seasonal patterns were detected in a study of cage-diving operations off of Haleiwa, Oahu. Galapagos shark abundance peaked during spring and summer months, followed by declines in the fall, with opposite trends recorded for sandbar sharks (Meyer et al. 2009b). In contrast, Galapagos sharks in the NWHI tend to be resident in specific islands or atolls, with limited movements between sites up to $10 \mathrm{~km}$ apart, primary foraging depths constrained to $\leq 100 \mathrm{~m}$, and indications of seasonal and diel patterns in visits to lagoonal habitats (Lowe et al. 2006, Meyer et al. 2010, Asher et al. 2017b). Further, tiger sharks exhibit a variety of movement behaviors, ranging from year-round residents at specific islands or atolls (suggesting consistent fidelity to groups of individual animals), interisland migrators of $\leq 100 \mathrm{~km}$, and long-distance travelers covering thousands of kilometers (Meyer et al. 2009a, 2010, Werry et al. 2014). Finally, movement behaviors of giant trevally at French Frigate Shoals are also mixed, with southern Rapture reef residents interlacing with other groups that seasonally migrate to Rapture Reef (from other parts of the atoll) to spawn (Lowe et al. 2006).

Taken together, seasonal migrations of largebodied predators are inherently complicated and varied, even within a single species. Therefore, we have no clear basis for drawing conclusions about the potential for differences in the timing of surveys by different methods to have biased our results. However, for each method, data are drawn from surveys encompassing large geographic areas, conducted in multiple years, mostly between July and October. There would certainly be value in adding future studies that consistently sample across constrained temporal periods and integrate data across a wide suite of methods.

\section{CONCLUSIONS}

In conclusion, assessments comparing large-bodied roving predators between remote versus human population centers remain challenging. Specific approaches may be needed to effectively measure the abundance of particular species, or research programs may need to incorporate a combination of methods. Overall, diver SPC surveys appear prone to substantial overestimation of relative NWHI:MHI abundance for nearly all of the predatory species examined. Similarly, towed-diver surveys likely overestimate MWHI:MHI ratios for several sharks and jack species (e.g. Caranx melampygus) but may provide more accurate estimates for other species such as Caranx ignobilis and Seriola spp., for which the towed-diver ARs were similar to those from RUVS and BRUVS surveys (pooled across all depths). RUVS and/or BRUVS might provide a less biased, holistic representation of NWHI:MHI predator ratios and possibly predator length-frequencies, given they can sample a greater depth range without the confounding behavioral effects or size-estimation discrepancies noted with divers; however, there may be reservations regarding the use of length-frequency data collected through any underwater visual census (diver or video) without first considering size-related behavioral responses (Harvey et al. 2013). Finally, the absence of several predators (e.g. Triaenodon obesus) from RUV and BRUV surveys in the MHI suggests that these methods may not be appropriate for sampling some predator species.

Diver-based visual surveys will undoubtedly continue to be used to assess coral reef fish assemblages, including predatory species, across the Hawaiian Archipelago and US Pacific Territories. However, this study and other recent works (Dale et al. 2011, Lindfield et al. 2014, Gray et al. 2016, Bradley et al. $2017 \mathrm{~b})$ underline the need for a careful selection of methods and an awareness of the potential for methodological bias, particularly for those roving predatory species that can visibly adjust their behavior in response to presence of divers, camera systems, and/or other stimuli. In our experience, the aggregation of sharks and jacks near divers is particularly noticeable in the NWHI; therefore, there would be considerable value in extending investigations to other methods in remote, predator-heavy ecosystems.

Acknowledgements. Scientific equipment, logistics, and funding support were provided by an IPRS/APA Scholarship, the University of Western Australia (UWA), Curtin University, NOAA Pacific Islands Fisheries Science Center (PIFSC), Ecosystem Sciences Division (ESD), NOAA Coral Reef Conservation Program (CRCP), NOAA PIFSC Science Operations Division (SOD), the Pacific Young Scientists Opportunity Program (PYSO), and the Papahānaumokuākea Marine National Monument. James Barlow, William Misa, Eric Mooney, and Louise Giuseffi from the NOAA PIFSC SOD, Dr. Benjamin Saunders from UWA, Marie Ferguson from the NOAA PIFSC ESD, and Mills Dunlap from the NOAA R/V 'Oscar Elton Sette' provided field assistance during data collection efforts. Hulali Kinilau, Karl Lindberg, and Andrew 
Gray assisted with videographic processing. Special thanks go to the commanding officers, captains, and crews of the NOAA research vessels 'Hi'ialakai', 'Oscar Elton Sette', the M/V 'Huki Pono', and the M/V 'Searcher'. Fish illustrations and methods graphics were generated by Amanda Dillon and Megan Asher (NOAA PIFSC ESD). Map by Tomoko Acoba (NOAA PIFSC ESD). All funders had no role in the study design, data collection and analysis, decision to publish, or preparation of this manuscript.

\section{LITERATURE CITED}

Asher J, Williams I, Harvey E (2017a) Mesophotic depth gradients impact reef fish assemblage composition and functional group partitioning in the Main Hawaiian Islands. Front Mar Sci 4:98

Asher J, Williams ID, Harvey ES (2017b) An assessment of mobile predator populations along shallow and mesophotic depth gradients in the Hawaiian Archipelago. Sci Rep 7:3905

Ayling AM, Choat JH (2008) Abundance patterns of reef sharks and predatory fishes on differently zoned reefs in the offshore Townsville region. Report by Sea Research for the Great Barrier Reef Marine Park Authority. Townsville, Honolulu, HI

Ayotte P, McCoy K, Heenan A, Williams I, Zamzow J (2015) Coral Reef Ecosystem Program standard operating procedures: data collection for rapid ecological assessment Fish surveys. Pacific Islands Fisheries Science Center Adm Rep H-15-07, Honolulu, HI

Bacheler NM, Shertzer KW (2015) Estimating relative abundance and species richness from video surveys of reef fishes. Fish Bull 113:15-27

Bailey DM, Priede IG (2002) Predicting fish behaviour in response to abyssal food falls. Mar Biol 141:831-840

* Barnett A, Abrantes KG, Seymour J, Fitzpatrick R (2012) Residency and spatial use by reef sharks of an isolated seamount and its implications for conservation. PLOS ONE 7:e36574

Bell J, Craik G, Pollard D, Russell B (1985) Estimating length frequency distributions of large reef fish underwater. Coral Reefs 4:41-44

Bowman AW, Azzalini A (1997) Applied smoothing techniques for data analysis: the kernel approach with S-Plus illustrations, Vol 18. Oxford University Press, Oxford

Bradley M, Baker R, Sheaves M (2017a) Hidden components in tropical seascapes: deep-estuary habitats support unique fish assemblages. Estuaries Coasts 40:1195-1206

Bradley D, Conklin E, Papastamatiou YP, McCauley DJ and others (2017b) Resetting predator baselines in coral reef ecosystems. Sci Rep 7:43131

Cappo M, Speare P, De'ath G (2004) Comparison of baited remote underwater video stations (BRUVS) and prawn (shrimp) trawls for assessments of fish biodiversity in inter-reefal areas of the Great Barrier Reef Marine Park. J Exp Mar Biol Ecol 302:123-152

Chambers J, Cleveland W, Kleiner B (1983) Graphical methods for data analysis. Wadsworth statistics/probability series. Duxley Press, Boston, MA

* Chapuis L, Collin SP, Yopak KE, McCauley RD and others (2019) The effect of underwater sounds on shark behaviour. Sci Rep 9:6924

Cole RG, Syms C, Davey NK, Gust N and others (2007) Does breathing apparatus affect fish counts and observations?
A comparison at three New Zealand fished and protected areas. Mar Biol 150:1379-1395

Colefax AP, Haywood MD, Tibbetts IR (2016) Effect of angling intensity on feeding behaviour and community structure of subtropical reef-associated fishes. Mar Biol 163:85

Colton MA, Swearer SE (2010) A comparison of two survey methods: differences between underwater visual census and baited remote underwater video. Mar Ecol Prog Ser 400:19-36

Compagno L (1984) FAO species catalogue, Vol. 4. Sharks of the world. An annotated and illustrated catalogue of sharks species known to date. Part 2: Carcharhiniformes. FAO Fish Synop 125. FAO, Rome

*Dale JJ, Meyer CG, Clark CE (2010) The ecology of coral reef top predators in the Papahānaumokuākea Marine National Monument. J Mar Biol 2011:725602

* Dale JJ, Stankus AM, Burns MS, Meyer CG (2011) The shark assemblage at French Frigate Shoals Atoll, Hawai'i: species composition, abundance and habitat use. PLOS ONE 6:e16962

*DeMartini EE, Friedlander AM (2004) Spatial patterns of endemism in shallow-water reef fish populations of the Northwestern Hawaiian Islands. Mar Ecol Prog Ser 271: 281-296

* DeMartini EE, Friedlander AM, Sandin SA, Sala E (2008) Differences in fish-assemblage structure between fished and unfished atolls in the northern Line Islands, central Pacific. Mar Ecol Prog Ser 365:199-215

* Dickens LC, Goatley CHR, Tanner JK, Bellwood DR (2011) Quantifying relative diver effects in underwater visual censuses. PLOS ONE 6:e18965

* Dorman SR, Harvey ES, Newman SJ (2012) Bait effects in sampling coral reef fish assemblages with stereo-BRUVs. PLOS ONE 7:e41538

Ellis DM, Demartini EE (1995) Evaluation of a video camera technique for indexing abundances of juvenile pink snapper, Pristipomoides filamentosus, and other Hawaiian insular shelf fishes. Fish Bull 93:67-77

Fedele AD (2017) Influences of catch-and-release angling on fish avoidance behavior. PhD dissertation, University of Nebraska, Lincoln, NB

Fitzpatrick R, Abrantes KG, Seymour J, Barnett A (2011) Variation in depth of whitetip reef sharks: Does provisioning ecotourism change their behaviour? Coral Reefs 30:569-577

Friedlander AM, DeMartini EE (2002) Contrasts in density, size, and biomass of reef fishes between the northwestern and the main Hawaiian islands: the effects of fishing down apex predators. Mar Ecol Prog Ser 230:253-264

*Friedlander AM, Sandin SA, DeMartini EE, Sala E (2010) Spatial patterns of the structure of reef fish assemblages at a pristine atoll in the central Pacific. Mar Ecol Prog Ser 410:219-231

Froese R, Pauly D (2014) FishBase. www.fishbase.org (accessed Nov 2014)

FFukunaga A, Kosaki RK, Wagner D, Kane C (2016) Structure of mesophotic reef fish assemblages in the northwestern Hawaiian Islands. PLOS ONE 11:e0157861

* Ghazilou A, Shokri M, Gladstone W (2016) Animal v. plant based bait: Does the bait type affect census of fish assemblages and trophic groups by baited remote underwater video (BRUV) systems? J Fish Biol 88:1731-1745

Gobush KS, Farry SC (2012) Non lethal efforts to deter shark predation of Hawaiian monk seal pups. Aquat Conserv 22:751-761 
Goetze J, Jupiter S, Langlois T, Wilson S, Harvey E, Bond T, Naisilisili W (2015) Diver operated video most accurately detects the impacts of fishing within periodically harvested closures. J Exp Mar Biol Ecol 462:74-82

Graham NAJ, Spalding MD, Sheppard CRC (2010) Reef shark declines in remote atolls highlight the need for multi-faceted conservation action. Aquat Conserv 20: $543-548$

* Gray AE, Williams ID, Stamoulis KA, Boland RC and others (2016) Comparison of reef fish survey data gathered by open and closed circuit SCUBA divers reveals differences in areas with higher fishing pressure. PLOS ONE 11:e0167724

Harvey ES, Shortis MR (1998) Calibration stability of an underwater stereo-video system: implications for measurement accuracy and precision. Mar Technol Soc J 32:3-17

Harvey ES, Cappo M, Butler JJ, Hall N, Kendrick GA (2007) Bait attraction affects the performance of remote underwater video stations in assessment of demersal fish community structure. Mar Ecol Prog Ser 350: 245-254

* Harvey ES, Newman SJ, McLean DL, Cappo M, Meeuwig JJ, Skepper CL (2012) Comparison of the relative efficiencies of stereo-BRUVs and traps for sampling tropical continental shelf demersal fishes. Fish Res 125-126: 108-120

Harvey E, McLean D, Frusher S, Haywood M, Newman S, Williams A (2013) The use of BRUVs as a tool for assessing marine fisheries and ecosystems: a review of the hurdles and potential (2011 National Workshop). Fisheries Research and Development Corporation and The University of Western Australia Project No. 2010/002

Henderson AR (2005) The bootstrap: a technique for datadriven statistics. using computer-intensive analyses to explore experimental data. Clin Chim Acta 359:1-26

Holzwarth SR, DeMartini EE, Schroeder R, Zgliczynski B, Laughlin J (2006) Sharks and jacks in the Northwestern Hawaiian Islands from towed-diver surveys 2000-2003. Atoll Res Bull 543:257-303

Januchowski-Hartley FA, Nash KL, Lawton RJ (2012) Influence of spear guns, dive gear and observers on estimating fish flight initiation distance on coral reefs. Mar Ecol Prog Ser 469:113-119

Langlois TJ, Harvey ES, Fitzpatrick B, Meeuwig JJ, Shedrawi G, Watson DL (2010) Cost-efficient sampling of fish assemblages: comparison of baited video stations and diver video transects. Aquat Biol 9:155-168

Langlois TJ, Fitzpatrick BR, Fairclough DV, Wakefield CB and others (2012) Similarities between line fishing and baited stereo-video estimations of length-frequency: novel application of kernel density estimates. PLOS ONE $7: \mathrm{e} 45973$

Lindfield SJ, McIlwain JL, Harvey ES (2014) Depth refuge and the impacts of SCUBA spearfishing on coral reef fishes. PLOS ONE 9:e92628

Loiseau N, Kiszka J, Bouveroux T, Heithaus M, Soria M, Chabanet P (2016) Using an unbaited stationary video system to investigate the behaviour and interactions of bull sharks Carcharhinus leucas under an aquaculture farm. Afr J Mar Sci 38:73-79

Lowe CG, Wetherbee BM, Meyer CG (2006) Using acoustic telemetry monitoring techniques to quantify movement patterns and site fidelity of sharks and giant trevally around French Frigate Shoals and Midway Atoll. Atoll Res Bull 543:281-303
MacNeil M, Graham N, Conroy M, Fonnesbeck C and others (2008) Detection heterogeneity in underwater visual census data. J Fish Biol 73:1748-1763

*McCauley DJ, McLean KA, Bauer J, Young HS, Micheli F (2012) Evaluating the performance of methods for estimating the abundance of rapidly declining coastal shark populations. Ecol Appl 22:385-392

McCoy KHA, Asher J, Ayotte P, Gorospe K and others (2017) Pacific Reef Assessment and Monitoring Program. Data report: ecological monitoring 2016: reef fishes and benthic habitats of the main Hawaiian Islands, Northwestern Hawaiian Islands, Pacific Remote Island Areas, and American Samoa. PIFSC Data Report DR-17-001:66. Pacific Islands Fisheries Science Center, Honolulu, HI

McGill R, Tukey JW, Larsen WA (1978) Variations of box plots. Am Stat 32:12-16

*Merson RR, Pratt HL (2001) Distribution, movements and growth of young sandbar sharks, Carcharhinus plumbeus, in the nursery grounds of Delaware Bay. Environ Biol Fishes 61:13-24

Meyer CG, Holland KN, Papastamatiou YP (2007a) Seasonal and diel movements of giant trevally Caranx ignobilis at remote Hawaiian atolls: implications for the design of marine protected areas. Mar Ecol Prog Ser 333:13-25

*Meyer CG, Papastamatiou YP, Holland KN (2007b) Seasonal, diel, and tidal movements of green jobfish (Aprion virescens, Lutjanidae) at remote Hawaiian atolls: implications for marine protected area design. Mar Biol 151: 2133-2143

Meyer CG, Clark TB, Papastamatiou YP, Whitney NM, Holland KN (2009a) Long-term movement patterns of tiger sharks Galeocerdo cuvier in Hawaii. Mar Ecol Prog Ser 381:223-235

*Meyer CG, Dale JJ, Papastamatiou YP, Whitney NM, Holland KN (2009b) Seasonal cycles and long-term trends in abundance and species composition of sharks associated with cage diving ecotourism activities in Hawaii. Environ Conserv 36:104-111

*Meyer CG, Papastamatiou YP, Holland KN (2010) A multiple instrument approach to quantifying the movement patterns and habitat use of tiger (Galeocerdo cuvier) and Galapagos sharks (Carcharhinus galapagensis) at French Frigate Shoals, Hawaii. Mar Biol 157: 1857-1868

Moffitt RB, Parrish FA (1996) Habitat and life history of juvenile Hawaiian pink snapper, Pristipomoides filamentosus. Pac Sci 50:371-381

* Mourier J, Maynard J, Parravicini V, Ballesta L, Clua E, Domeier ML, Planes S (2016) Extreme inverted trophic pyramid of reef sharks supported by spawning groupers. Curr Biol 26:2011-2016

Nadon MO (2017) Stock assessment of the coral reef fishes of Hawaii, 2016. NOAA Tech Memo NMFS-PIFSC-60

* Nadon MO, Baum JK, Williams ID, McPherson JM and others (2012) Re-creating missing population baselines for pacific reef sharks. Conserv Biol 26:493-503

Nadon MO, Ault JS, Williams ID, Smith SG, DiNardo GT (2015) Length-based assessment of coral reef fish populations in the Main and northwestern Hawaiian islands. PLOS ONE 10:e0133960

Nakamura I, Watanabe YY, Papastamatiou YP, Sato K, Meyer CG (2011) Yo-yo vertical movements suggest a foraging strategy for tiger sharks Galeocerdo cuvier. Mar Ecol Prog Ser 424:237-246 
Newman MJ, Paredes GA, Sala E, Jackson JB (2006) Structure of Caribbean coral reef communities across a large gradient of fish biomass. Ecol Lett 9:1216-1227

Papastamatiou YP, Wetherbee BM, Lowe CG, Crow GL (2006) Distribution and diet of four species of carcharhinid shark in the Hawaiian Islands: evidence for resource partitioning and competitive exclusion. Mar Ecol Prog Ser 320:239-251

Papastamatiou YP, Meyer CG, Kosaki RK, Wallsgrove NJ, Popp BN (2015) Movements and foraging of predators associated with mesophotic coral reefs and their potential for linking ecological habitats. Mar Ecol Prog Ser 521:155-170

Parrish FA, Marshall GJ, Buhleier B, Antonelis GA (2008) Foraging interaction between monk seals and large predatory fish in the Northwestern Hawaiian Islands. Endang Species Res 4:299-308

Pickard AE (2013) Characterization of shark movements on a mesophotic Caribbean coral reef and temporal association with fish spawning aggregations. MSc thesis, Nova Southeastern University, Davie, FL

Polis GA, Anderson WB, Holt RD (1997) Toward an integration of landscape and food web ecology: the dynamics of spatially subsidized food webs. Annu Rev Ecol Syst 28: 289-316

类 Core Team (2016) R: a language and environment for statistical computing, v. 3.3.0. R Foundation for Statistical Computing, Vienna, www.R-project.org

* Richards BL, Williams ID, Nadon MO, Zgliczynski BJ (2011) A towed-diver survey method for mesoscale fisheryindependent assessment of large-bodied reef fishes. Bull Mar Sci 87:55-74

Rizzari JR, Frisch AJ, Connolly SR (2014) How robust are estimates of coral reef shark depletion? Biol Conserv 176: 39-47

Ruppert JLW, Travers MJ, Smith LL, Fortin MJ, Meekan MG (2013) Caught in the middle: combined impacts of shark removal and coral loss on the fish communities of coral reefs. PLOS ONE 8:e74648

Salinas de León P, Acuña-Marrero D, Rastoin E, Friedlander AM, Donovan MK, Sala E (2016) Largest global shark biomass found in the northern Galápagos Islands of Darwin and Wolf. PeerJ 4:e1911

Sandin SA, Sampayo EM, Vermeij MJ (2008a) Coral reef fish and benthic community structure of Bonaire and Curaçao, Netherlands Antilles. Caribb J Sci 44:137-144

Sandin SA, Smith JE, DeMartini EE, Dinsdale EA and others (2008b) Baselines and degradation of coral reefs in the northern Line Islands. PLOS ONE 3:e1548

Santos SR, Xiang Y, Tagawa AW (2011) Population structure and comparative phylogeography of jack species (Caranx ignobilis and $C$. melampygus) in the high Hawaiian Islands. J Hered 102:47-54

Schobernd ZH, Bacheler NM, Conn PB (2014) Examining the utility of alternative video monitoring metrics for indexing reef fish abundance. Can J Fish Aquat Sci 71: 464-471

Schroeder RE, Parrish JD (2006) Ecological characteristics of coral patch reefs at Midway Atoll, northwestern Hawaiian Islands. Atoll Res Bull 543:439-460

Schwarz FJ (2004) Biological features of five poorly known carangid fishes frequenting inland and ocean waters of North Carolina. J NC Acad Sci 120:99-105

Seager J (2008) SEAGIS CAL and Photomeasure stereo photogrametric calibration and analysis software. www. seagis.com.au
Sheather SJ, Jones MC (1991) A reliable data-based bandwidth selection method for kernel density estimation. J R Stat Soc B 53:683-690

Sheaves M, Johnston R, Baker R (2016) Use of mangroves by fish: new insights from in-forest videos. Mar Ecol Prog Ser 549:167-182

Shortis MR, Harvey ES (1998) Design and calibration of an underwater stereo-video system for the monitoring of marine fauna populations. Int Arch Photogramm Remote Sens 32:792-799

Smith SJ (1997) Bootstrap confidence limits for groundfish trawl survey estimates of mean abundance. Can J Fish Aquat Sci 54:616-630

Smith KR, Scarpaci C, Otway NM (2016) Scuba diving tourism impacts and environmental influences on the patrolling behavior of grey nurse sharks (Carcharias taurus): a preliminary assessment using acoustic telemetry at Fish Rock, Australia. Tour Mar Environ 12:17-34

Speed CW, Meekan MG, Field IC, McMahon CR and others (2011) Spatial and temporal movement patterns of a multi-species coastal reef shark aggregation. Mar Ecol Prog Ser 429:261-275

* Stobart B, Garcia-Charton JA, Espejo C, Rochel E and others (2007) A baited underwater video technique to assess shallow-water Mediterranean fish assemblages: methodological evaluation. J Exp Mar Biol Ecol 345:158-174

* Stobart B, Diaz D, Alvarez F, Alonso C, Mallol S, Goni R (2015) Performance of baited underwater video: Does it underestimate abundance at high population densities? PLOS One 10:e0127559

Tagawa AW, Tam CK (2006) Hawaii's ulua and papio tagging project 2000 to 2004. Division of Aquatic Resources, Department of Land and Natural Resources, Honolulu, HI

* Tamaru CS, Klinger Bowen RC, Ogawa K, Iwaki T, Kurashima A, Itoh N (2016) Prevalence and species identity of Trypanorhyncha in cultured and wild amberjack, Seriola spp. in Hawaii-implications for aquaculture. J World Aquacult Soc 47:42-50

* Trebilco R, Dulvy NK, Anderson SC, Salomon AK (2016) The paradox of inverted biomass pyramids in kelp forest fish communities. Proc R Soc B 283:20160816

V Vaudo JJ, Wetherbee BM, Harvey G, Nemeth RS and others (2014) Intraspecific variation in vertical habitat use by tiger sharks (Galeocerdo cuvier) in the western North Atlantic. Ecol Evol 4:1768-1786

*Vianna GMS, Meekan MG, Meeuwig JJ, Speed CW (2013) Environmental influences on patterns of vertical movement and site fidelity of grey reef sharks (Carcharhinus amblyrhynchos) at aggregation sites. PLOS ONE 8: e60331

Walsh AT, Barrett N, Hill N (2016) Efficacy of baited remote underwater video systems and bait type in the cool-temperature zone for monitoring 'no-take' marine reserves. Mar Freshwater Res 68:568-580

Wand M, Jones M (1995) Kernel smoothing. Monographs on statistics and applied probability, Vol 60. Chapman \& Hall, London

*Wand M, Ripley B (2011) KernSmooth: functions for kernel smoothing for Wand \& Jones (1995). R package version 223-15. https://cran.r-project.org/web/packages/Kern Smooth/index.html (accessed 1 July 2016)

*Wang H, Morrison W, Singh A, Weiss HH (2009) Modeling inverted biomass pyramids and refuges in ecosystems. Ecol Model 220:1376-1382 
Ward-Paige C, Flemming JM, Lotze HK (2010a) Overestimating fish counts by non-instantaneous visual censuses: consequences for population and community descriptions. PLOS ONE 5:e11722

Ward-Paige CA, Mora C, Lotze HK, Pattengill-Semmens C, McClenachan L, Arias-Castro E, Myers RA (2010b) Large-scale absence of sharks on reefs in the GreaterCaribbean: a footprint of human pressures. PLOS ONE 5: e11968

Watson DL, Harvey ES (2007) Behaviour of temperate and sub-tropical reef fishes towards a stationary SCUBA diver. Mar Freshwat Behav Physiol 40:85-103

Watson DL, Harvey ES, Anderson MJ, Kendrick GA (2005) A comparison of temperate reef fish assemblages recorded by three underwater stereo-video techniques. Mar Biol 148:415-425

Watson DL, Harvey ES, Fitzpatrick BM, Langlois TJ, Shedrawi G (2010) Assessing reef fish assemblage structure: How do different stereo-video techniques compare? Mar Biol 157:1237-1250

Werry JM, Planes S, Berumen ML, Lee KA, Braun CD, Clua E (2014) Reef-fidelity and migration of tiger sharks, Galeocerdo cuvier, across the Coral Sea. PLOS ONE 9:e83249

Wetherbee BM, Crow GL, Lowe CG (1997) Distribution, reproduction and diet of the gray reef shark Carcharhinus amblyrhynchos in Hawaii. Mar Ecol Prog Ser 151: 181-189

Whitney NM, Papastamatiou YP, Holland KN, Lowe CG (2007) Use of an acceleration data logger to measure diel activity patterns in captive whitetip reef sharks, Triaenodon obesus. Aquat Living Resour 20:299-305

Whitney NM, Pyle RL, Holland KN, Barcz JT (2012) Movements, reproductive seasonality, and fisheries interactions in the whitetip reef shark (Triaenodon obesus)

Editorial responsibility: Janet Ley, St. Petersburg, Florida, USA from community-contributed photographs. Environ Biol Fishes 93:121-136

Williams ID, Richards BL, Sandin SA, Baum JK and others (2011) Differences in reef fish assemblages between populated and remote reefs spanning multiple archipelagos across the central and western Pacific. J Mar Biol 2011: $1-14$

Williams I, Zamzow J, Lino K, Ferguson M, Donham E (2012) Status of coral reef fish assemblages and benthic condition around Guam: a report based on underwater visual surveys in Guam and the Mariana Archipelago, AprilJune 2011. NOAA Tech Memo NMFS-PIFSC-33

Williams ID, White DJ, Sparks RT, Lino KC, Zamzow JP, Kelly EL, Ramey HL (2016) Responses of herbivorous fishes and benthos to 6 years of protection at the Kahekili Herbivore Fisheries Management Area, Maui. PLOS ONE 11:e0159100

Willis TJ, Babcock RC (2000) A baited underwater video system for the determination of relative density of carnivorous reef fish. Mar Freshw Res 51:755-763

WWillis TJ, Millar RB, Babcock RC (2000) Detection of spatial variability in relative density of fishes: comparison of visual census, angling, and baited underwater video. Mar Ecol Prog Ser 198:249-260

Wilson S, Graham N, Polunin N (2007) Appraisal of visual assessments of habitat complexity and benthic composition on coral reefs. Mar Biol 151:1069-1076

Wraith JA (2007) Assessing reef fish assemblages in a temperate marine park using baited remote underwater video. MS thesis, University of Wollongong

*Yulianto I, Hammer C, Wiryawan B, Pardede S, Kartawijaya T, Palm H (2015) Improvement of fish length estimates for underwater visual census of reef fish biomass. J Appl Ichthyology 31:308-314

Submitted: February 20, 2019; Accepted: August 19, 2019 Proofs received from author(s): November 4, 2019 